TAO, Vol. 15, No. 5, 949-981, December 2004

\title{
Simulations of Asian Yellow Dust Incursion Over Taiwan for the Spring of 2002 and 2003
}

\author{
Jen-Ping Chen ${ }^{1, *}$, Zifa Wang ${ }^{2}$, Chea-Yuan Young ${ }^{3}$, Fujung Tsai ${ }^{1}$, I-Chun Tsai ${ }^{1}$, \\ Guan-Jyh Wang ${ }^{1}$, Wei-Chun Shieh ${ }^{1}$, Hsiao-Wen Lin ${ }^{1}$, Jing-Yun Huang ${ }^{1}$, and Ming-Jeh Lu ${ }^{1}$
}

(Manuscript received 24 December 2003, in final form 8 November 2004)

\begin{abstract}
Dust storms that occurred in East Asia during the spring of 2002 and 2003 were simulated by a regional dust deflation and transport model. Particular focus was placed on dust incursion events over Taiwan. Two of the events were analyzed in detail to give a complete picture of the three dimensional transport patterns. The general characteristics of dust incursion events were summarized, including the source locations, transport route and distribution pattern in three dimensions, traveling time, duration of incursion, and the seasonal spatial distribution of dust concentration. Significant differences were also found in these characteristics between the two years, the main cause of which was a change in regional climate patterns. The performance of the model developed for this study was evaluated against other dust forecast models, and found to have superior capability for forecasting in the Taiwan area.
\end{abstract}

(Key words: Dust storm, Operational forecast, TAQM, Dust transport)

\section{INTRODUCTION}

Large-scale dust storms, originating at the northern and northwestern China, frequently occur during springtime (Duce 1980; Sun et al. 2001). During dust storm events, dust concentration in the atmosphere can be elevated to a level that adversely impacts on various economic activities and poses serious health risks and safety concerns, including that for ground

\footnotetext{
${ }^{1}$ Department of Atmospheric Sciences, National Taiwan University, Taiwan, ROC

2 Institute of Atmospheric Physics, Chinese Academy of Sciences

3 Environmental Protection Administration, Taiwan, ROC

* Corresponding author address: Prof. Jen-Ping Chen, Department of Atmospheric Sciences, National Taiwan University, Taipei, Taiwan, ROC; E-mail: jpchen@webmail.as.ntu.edu.tw
} 
and aviation transportation. These airborne dust particles are often termed yellow dust, mineral aeorsols or kosa. They potentially influence cloud and precipitation formation, radiative transfer, and chemical processes in the atmosphere, and impact on the ecology of land and sea (Eppley 1980; Duce 1986; Guieu et al. 2001). Under appropriate meteorological setups, yellow dust can be transported to areas that are hundreds and even thousands of kilometers away. Regions that are affected the most include the Northeast and Southeast China, Korea, Japan, Taiwan and Southeast Asia. On occasions, the elevated dust particles were transported across the Pacific, as far as North American (Merrill et al. 1989; Wilkening et al. 2000).

The frequent occurrence of dust storms in China during the past decade has raised public health concerns in Taiwan. In past studies, post-analysis of observational data was generally conducted to describe the influence of yellow dust on the Taiwan region (Young et al. 1997). Operational forecasts of dust incursion, on the other hand, were limited to synoptic meteorological analyses, which provide crude information on spatial and temporal changes and little about dust particle concentration in the air. The impact of dust events and increasing public concern warrants the development of an approach, which provides an advanced and precise early warning system. Research in this area would benefit from a better understanding of dust deflation and transport mechanisms.

Numerical models that simulate the deflation and transport of dust particles are potentially powerful tools for fundamental research and daily forecast operations. Currently, only a few models have been developed for these purposes. The Georgia Tech/Goddard Global Ozone Chemistry Aerosol Radiation Transport model (GOCART; Chin et al. 2003) was applied to support the ACE-Asia field campaign, generating a 3-day aerosol product forecast, and the Harvard University group used TRACE-P Robotic Automatic Processing System (TRAPS), during the TRACE-P campaign (cf. Heald et al. 2003). There are also operation models that routinely provide dust forecasts, such as the Navy Aerosol Analysis and Prediction System (NAAPS; Liu et al. 2003), which provides global dust forecasts, and the modeling system developed by the Euro-Mediterranean Centre on Insular Coastal Dynamics (ICoD), which provides dust forecasts for the Euro-Mediterranean and Far Eastern regions (cf. Nickovic et al. 2001). Research-mode models that focus solely on the East Asia region include the weather Chemical Forecasting System (CFORS; Uno et al. 2003), developed by the Kyushu University group, and the Nested Air Quality Prediction Modeling System (NAQPMS; Wang et al. 2001), of the Institute of Atmospheric Physics, Chinese Academy of Sciences. These systems provide real-time forecast of dust storms over East Asia.

The purpose of this study was to develop a modeling system that simulates dust deflation into the atmosphere and subsequent transport in the East Asian region. The Environmental Protection Administration of the Republic of China (Taiwan EPA) uses this modeling system, as part of an early-warning system, to provide public health alerts regarding air quality. This system was also used to provide lead-time for operations of in a field experiment conducted in Taiwan during the spring of 2001 (cf. Chou et al. 2004; Lung et al. 2004; Hsu et al. 2004; Wang et al. 2004; Yuan et al. 2004). In this study then particular attention was paid to the region of Taiwan, for analysis of dust incursion events simulated by the model and evaluation of model performance against observations and other similar models. 


\section{MODEL DESCRIPTION}

The model applied in the simulation of atmospheric dust transport consisted of three major components: a meteorological module, a dust deflation module, and a transport module. The widely used Fifth-Generation PSU/NCAR Mesoscale Meteorological Model (MM5) was applied to provide regional meteorological fields. The dust deflation module used for this study followed the scheme of Wang et al. (2000). This scheme describes the deflation of dust into the atmosphere in terms of surface type, friction velocity and relative humidity near the surface, as well as the synoptic pattern. Twelve classes of dust particles in the size range of 0.5 to $30 \mu \mathrm{m}$ in diameter were applied. When the friction velocity or surface wind velocity and relative humidity exceeded their thresholds, dust was emitted into the atmosphere with source strength of:

$$
S=C_{1} C_{2}\left(u^{*}\right)^{2}(1-R H) \cdot W
$$

where $S$ is in $\mathrm{kg} \mathrm{m}^{-2} \mathrm{~s}^{-1}, C_{1}\left(=2.9 \times 10^{-11}\right)$ is an empirical constant, $C_{2}$ is a coefficient representing different surface types (e.g., desert, semi-arid, grass land, etc.), $u^{*}$ is the surface friction velocity, $R H$ is the relative humidity (with a value of $0 \sim 1$ ) near the surface, and $W$ is the mass fraction of each class of dust relative to total dust mass. Here, $C_{2}$ and $W$ are empirically determined for each grid point according to field investigations, whereas $u^{*}$ and $R H$ are provided by the MM5 meteorological calculation.

Dust transport in the regional scale was calculated using the Taiwan Air Quality Model (TAQM). The Taiwan EPA first established this model in 1993 by modifying the Regional Acid Deposition Model (RADM) developed by the US National Acid Precipitation Assessment Program. The version used for this study was the second generation TAQM established in 1999. This model incorporates advanced numerical schemes that improve the precision and efficiency of computation. However, only the transport and dispersion core were used, with all chemical transformation mechanisms in TAQM turned off, to reduce computation time. The dust deflation module is actually embedded in TAQM and functions as an emission source processor. For the purpose of this study, this combination was termed the "TAQM/kosa" model. The execution of TAQM/kosa was conducted offline, using pre-calculated meteorological fields, from MM5, as input.

The transport scheme in TAQM takes into account horizontal and vertical advection, eddy diffusion, and local convective mixing that can occur with unstable weather conditions (Pleim and Chang 1992). To avoid strong numerical diffusion, the Bott Scheme (Bott 1989) was adopted for the advection calculation. In addition to transport, the deposition of dust particles, including dry deposition at the lowest layer, gravitational settlement at all layers, and washout (below cloud scavenging) were also taken into account. The calculation of washout efficiency followed the formula of Pruppacher and Klett (1978):

$$
\Lambda=10.8 \cdot E \cdot R^{0.16} / H
$$


where $E$ is the coagulation coefficient, which is set as 0.83 according to Wang et al. (2000), $R$ is the precipitation rate (in $\mathrm{mm} \mathrm{hr}^{-1}$ ), and $H$ is the sub-cloud layer thickness (in m).

Both MM5 and TAQM apply the Cartesian coordinates in the horizontal domain with Lambert conformal projection (suitable for the mid-latitude regions covered by this study), and $\sigma$-coordinate in the vertical direction. The model domain was set on the East Asian region, covering the dust source in Northern/Northwestern China and the Mongolia region, as well as the receptor region of Taiwan. The horizontal grid resolutions were fixed at $81 \mathrm{~km}$ by $81 \mathrm{~km}$, whereas the vertical resolution was non-uniformed. MM5 was set to 25 layers in the vertical. However, TAQM was set to 15 layers (at sigma levels $=0.998,0.992,0.983,0.967,0.942,0$. $909,0.869,0.799,0.7,0.6,0.5,0.4,0.3,0.2,0.075)$ with the resolution finest from about $40 \mathrm{~m}$ at the base and coarsen to about $2 \mathrm{~km}$ at the top. A 5-min time step was used for both MM5 and TAQM.

The MM5 meteorological simulations were run in non-hydrostatic mode, using the $1^{\circ} \times 1^{\circ}$ reanalysis data (including sea surface temperature) and global AVN forecast data of the US National Center of Environmental Prediction (NCEP) as the initial and boundary conditions, respectively. There was no observation of dust concentrations for initialization using TAQM/kosa, so $24^{\text {th }}$ hour output of dust concentrations were maintained and used as initial conditions for the forecast of the next day. A 96-hour forecast was conducted for the day of operation.

\section{DETAILED ANALYSIS OF TWO EVENTS}

The TAQM/kosa model was applied to conduct operational forecasts of dust incursion events during the spring (February 1 to May 31) of 2002 and 2003. A detailed discussion of two case studies for episodes that occurred during late March of each year are presented in this section to demonstrate typical dust deflation and transport patterns. General characteristics of all episodes are summarized in the next section.

\subsection{Case 1: A "Storm Trooper" with Returning Flow (March 18 22, 2002)}

Between March 15 and 16, 2002, strong winds developed between the Mongolian highlow dipole system, where the isobars are closely packed and longitudinally aligned as shown on the surface weather map of Fig. 1a. Since this high-wind spot coincided with the desert area underneath, widespread windblown dust was initiated. This dust deflation was well captured by the TAQM/kosa model (see Fig. 2a). On the $500 \mathrm{hPa}$ weather map (not shown) a deep trough was found to lie directly on top of this high wind region. The southeasterly flow on the lee side of this trough brought down the cold northern air and strengthened the surface highpressure system. While the surface high-pressure center moved along with the upper-air flow and migrated towards the southeast on March 17 (Fig. 1b), the cold air outburst at the leading edge of the surface high accelerated, forming a high-pressure ridge that stretched toward the southeast. This ridge split into a sub-high the next day and brought a cold northeast flow to Taiwan, following a swift frontal passage (Fig. 1c). The sub-high then cutoff from the main ridge and entered the East China Sea at 20 knots. A "returning flow" synoptic pattern was quickly established. Consequently, the leading air mass of the cutoff high that was headed east 
toward the Pacific turned clockwise and moved westbound toward Taiwan (Fig. 1d). With such a unique meteorological setup, the road trip of yellow dust to Taiwan was clearly mapped out, and these details were well captured by the model, as described below.

(a)

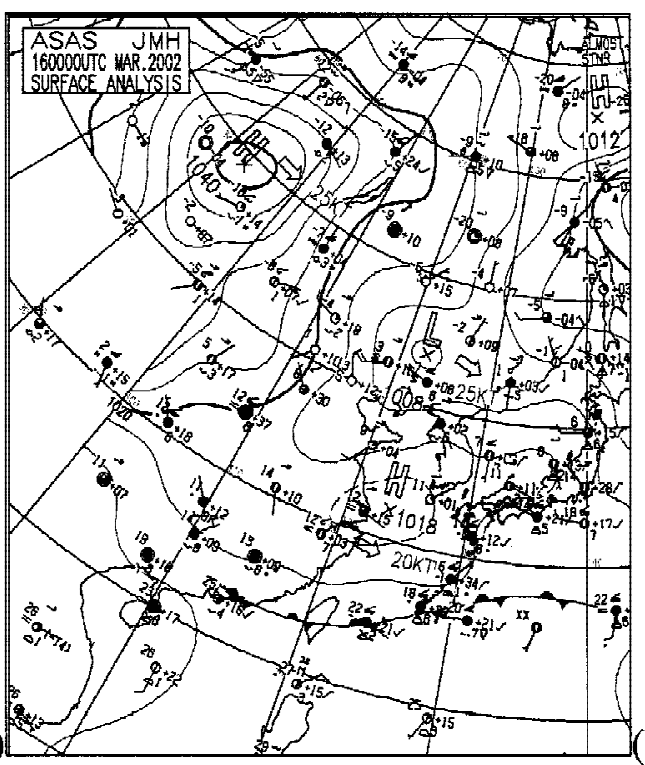

(b)
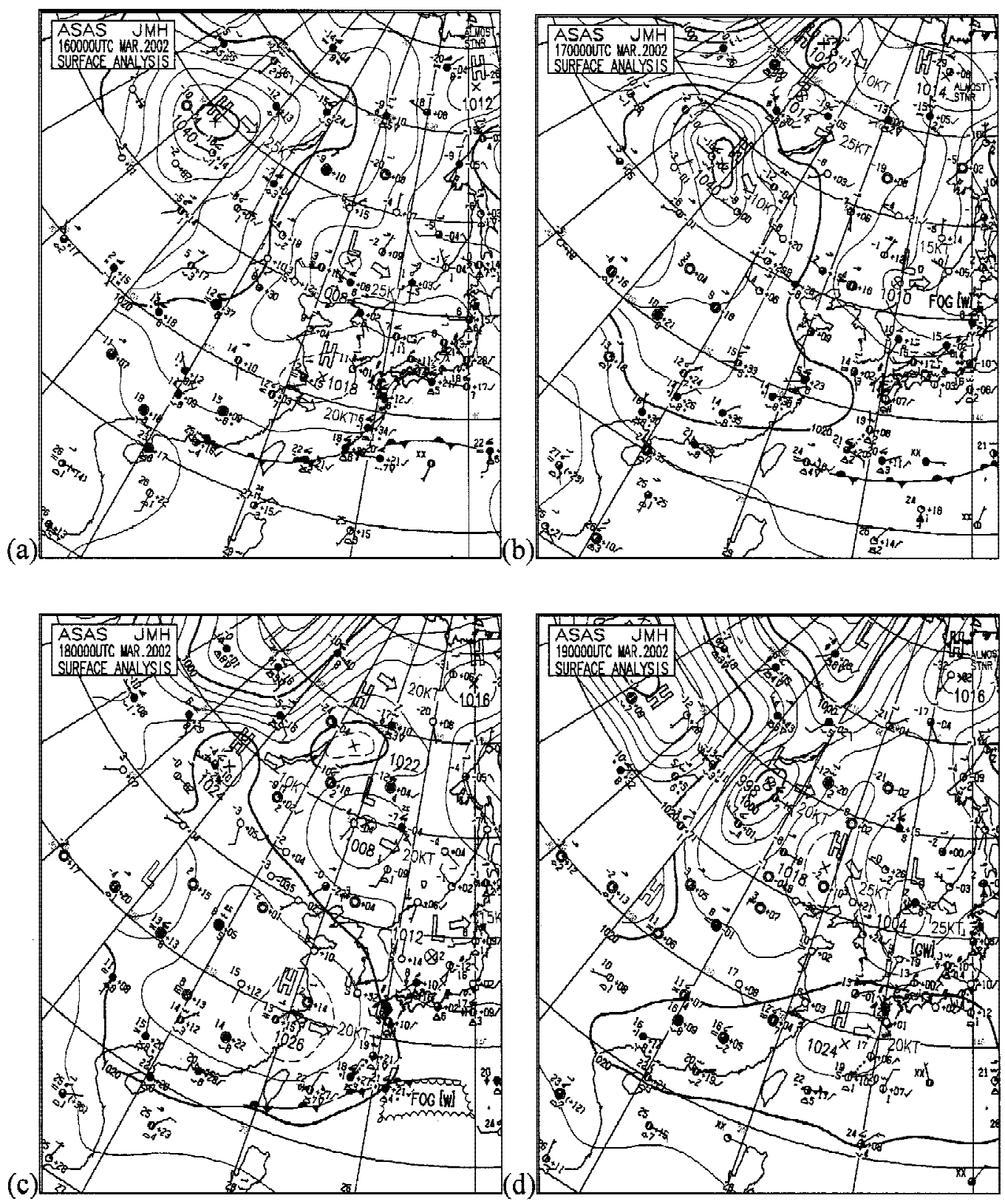

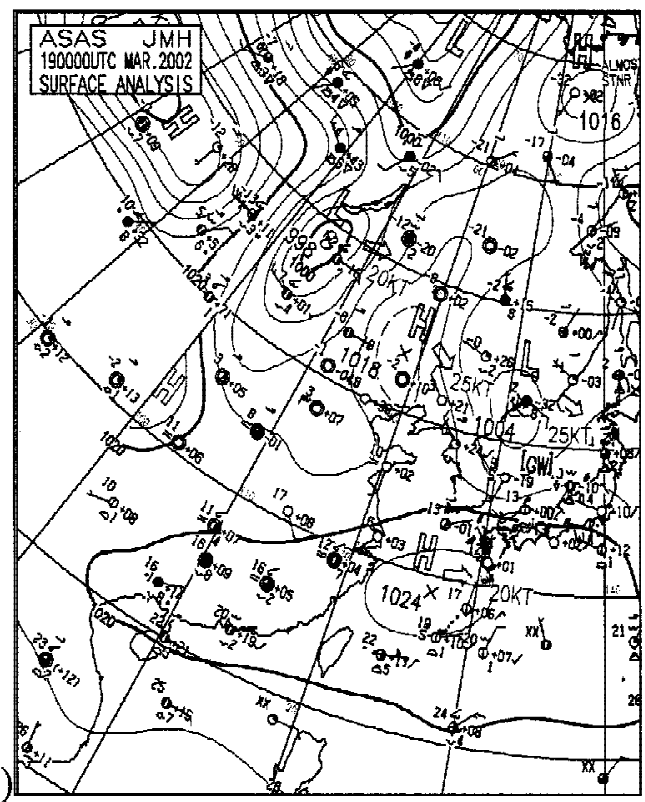

Fig. 1. Surface weather map for the dust incursion event of March 18 20, 2002. 
The cold air outburst in northern China not only stirred the yellow dust up into the atmosphere but also acted as an air-transport carrier. Figure 2 shows the journey of the simulated dust load at the near-ground level. On each panel two dusty-air parcels were marked to trace their individual paths, which clearly demonstrate the evolution of the dusty air from the deflation stage (Fig. 2a) to the arrival over Taiwan (Fig. 2f), in a six-day sequence. Thick circles marked the path of Parcel A and dotted circles marked that of Parcel B. The travel paths were determined by HYSPLIT trajectory analyses and by examining the animation of model results. The two parcels were initiated in two adjacent areas inside Mongolia at about the same time but separated further apart as they traveled toward the southeast. Parcel A was stretched into a long curved belt while invading Korea and Japan on the March 17 and 18, and Parcel B went by way of central China almost straight toward Taiwan. As the airflow suddenly slowed and changed direction, the leading edge of Parcel B became hook-shaped while merging with the tail of Parcel A. The overlapping area was the first portion to invade Taiwan, at around midday on March 18. In the mean time, Parcel A became increasingly stretched to the point where it eventually split in the middle. A comparison of Fig. 1d demonstrates that this belt appeared to mark the southern boundary of the continental air mass (the cutoff high) that entered the East China Sea.

Figure 3 depicts the $\mathrm{PM}_{10}$ concentration measured at two coastal stations, Wanli and ILan, and the Yangming Mountain station in northern Taiwan, all of which located within one grid area of the model. A sharp rise in $\mathrm{PM}_{10}$ that may indicate the arrival of yellow dust can be found at all these stations, but at different times. Data analysis of several events for the Wanli (WL) station indicated that a high amount of sea salt was often produced directly after the passage of the cold front but before the arrival of dust at the station. This result could be due to the station's unique geographic relationship with the northeast monsoon. Analysis of chemical composition of aerosols collected at this site also indicated the presence of a large proportion of sea salt (cf. Wang et al. 2004; Lung et al. 2004; Chou et al. 2004). This would explain why the $\mathrm{PM}_{10}$ concentration at Wanli during the dust incursion events frequently had higher peak values and rises much earlier than at the other stations. The I-Lan and Yangming data however indicated that the model developed for this study captured the timing of this dust incursion rather well. Note that the observations seem to exhibit a double peak pattern, as did the simulated results. Figure $2 \mathrm{f}$ demonstrates that the second peak was caused by the returning flow of the cutoff high, which brought back dust of Parcel A from the east. Such a double-peak (and sometimes even multi-peak) phenomenon, associated with a returning flow synoptic pattern, was quite common during 2002 and 2003, with the second wave of dust often stronger than the first.

The simulated horizontal distributions of near-surface dust load were found to correlate reasonably well with several observational data, including regional meteorological surface observations, Chinese urban air quality data $\left(\mathrm{PM}_{10}\right)$ and satellite images. Another good comparison was also demonstrated in Fig. 4, which is a composite map of weather reports on dustrelated atmospheric phenomena for the date of March 19. Here, the distribution patterns show several distinct features that were captured by the simulations depicted in Fig. 2e, such as the wide spread dust over Mongolia, northern and northeastern China and the entire region of the Korean peninsula. The area void of dust between $20 \sim 30^{\circ} \mathrm{N}$ and around $110^{\circ} \mathrm{E}$ in southern 


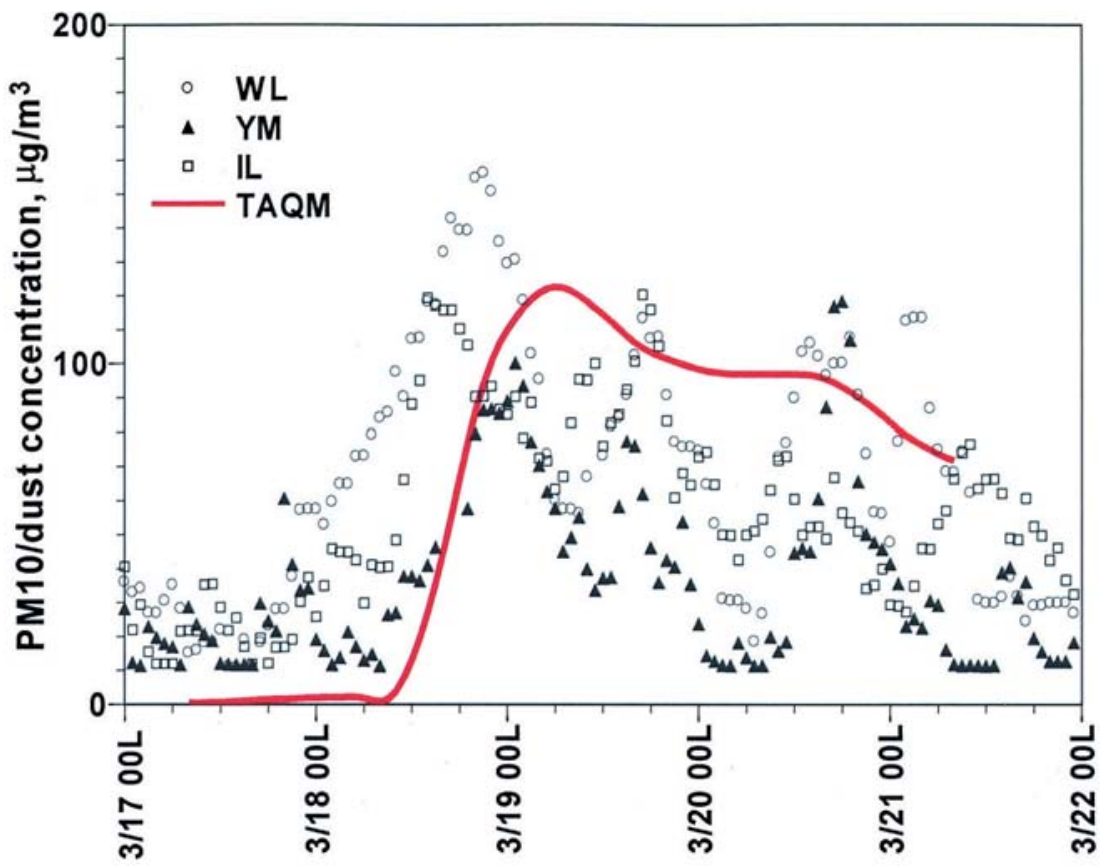

Fig. 3. Hourly values of the simulated dust loading (thick line) and the observed $\mathrm{PM}_{10}$ values (symbols). The thick line represents forecasts made one day prior to the dust incursion on March 18, 2002. The stations Wanli (WL) and I-Lan (IL) are located at the northern and northeastern coasts, respectively; whereas Yanming (YM) is an elevated station (about 800 $\mathrm{m}$ above sea level) in the northern mountain area.

China also matched quite well. Even the dust-belt that passed through Taiwan can be identified, by connecting reports from island stations in the East China Sea, south of Japan, to the coastal stations in southeastern China. Note that there were reports of haze over the whole of Taiwan, and yellow dust probably contributed significantly to the hazy phenomenon on this day.

The vertical structure of the dusty air mass is an important factor to the occurrence of dust incursion events, but no information about this phenomenon can be derived from the aforementioned observations. A vertical cross-section of the simulations, depicted in Fig. 5, indicate that the dusty air mass might have a delicate vertical structure. Note that the sigma coordinate of Fig. 5 roughly corresponds to pressure and height values of Fig. 6. Near the source region (Fig. 5a) the upper part of the dusty air column was tilted toward the east due to stronger winds aloft. Some of the dust could have been lifted to high elevations by the strong upward air motion associated with a low-pressure system (see Fig. 1). The tilting may have persisted, such that a dust layer overhung atop another dust layer formed earlier, as shown in 
Figs. 5a, b and the strong upper-air winds may have carried the dust aloft to the east, shortly thereafter, and so out of the model domain. In some cases (but not this one), high-level dust, caught by a strong jet stream, can travel all the way across the Pacific. In this case, the yellow dust gradually descended due to large-scale atmospheric subsidence and gravitational settlement, while traveling with the surface sub-high entering the Pacific. Before reaching Taiwan, the dust parcels were mostly confined to the lower troposphere. Figure $5 \mathrm{c}$ shows the leading edge of Parcel B, which was about 1-km thick, remained close to the surface, on approaching Taiwan. Figure 5d indicates that the mass center of Parcel A was actually 2 to $3 \mathrm{~km}$ above sea level. However, verification of the modeled vertical structure was limited, without a vertical profiling instrument, such as lidar,

Figure 3 depicts data from the Yangming mountain station. Yangming is normally very low in $\mathrm{PM}_{10}$, so when a peak in $\mathrm{PM}_{10}$ demonstrates a dust load, the thickness of the dust may

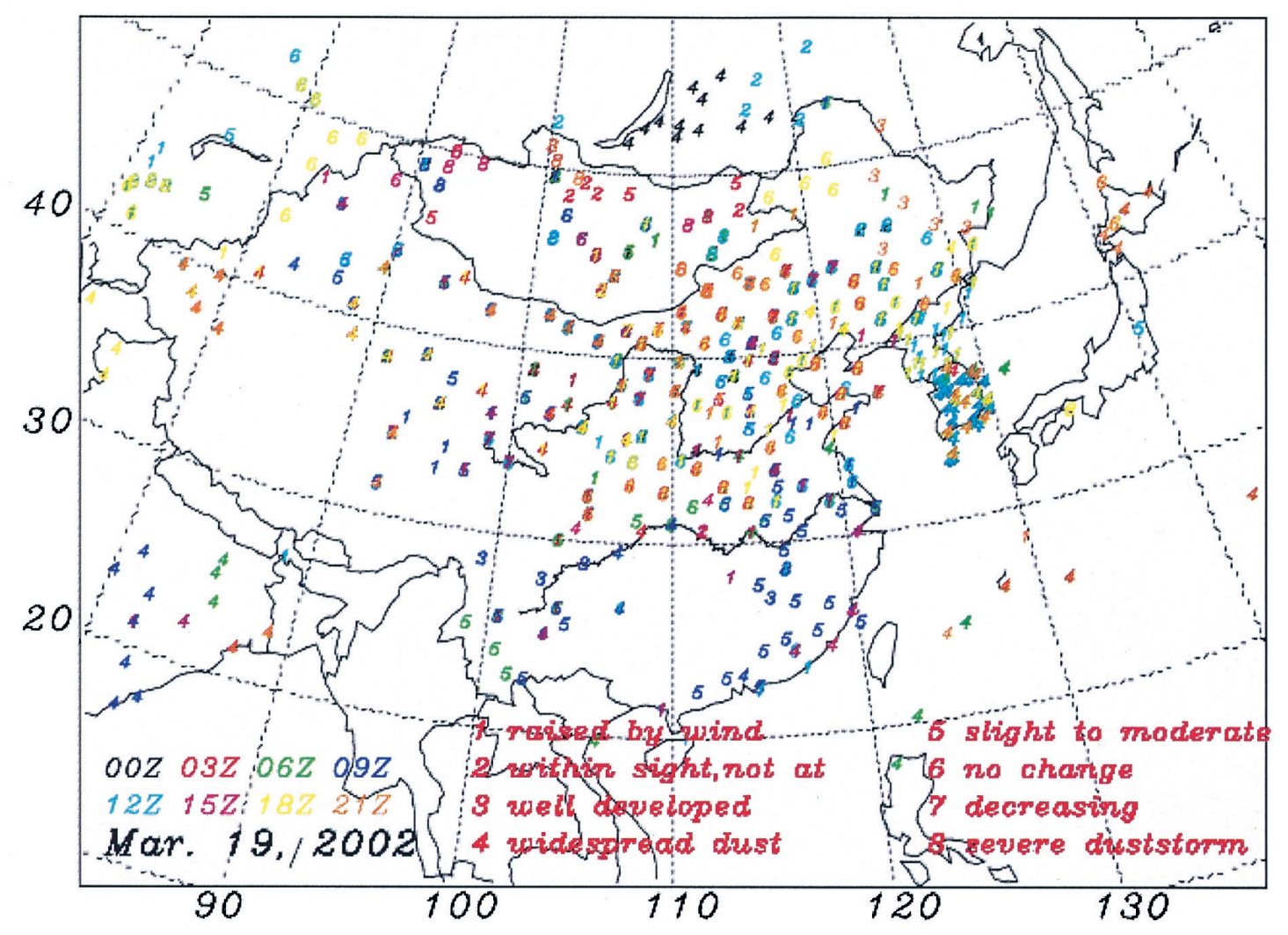

Fig. 4. Weather report on dust-related phenomena on March 19, 2002. All digits indicate that dust was observed at or near the station, with exact meanings listed at the lower part of the figure; whereas the 8 different colors represent different times (in three-hour intervals) that the reports were made, with corresponding times given at the lower left corner. 
(a)

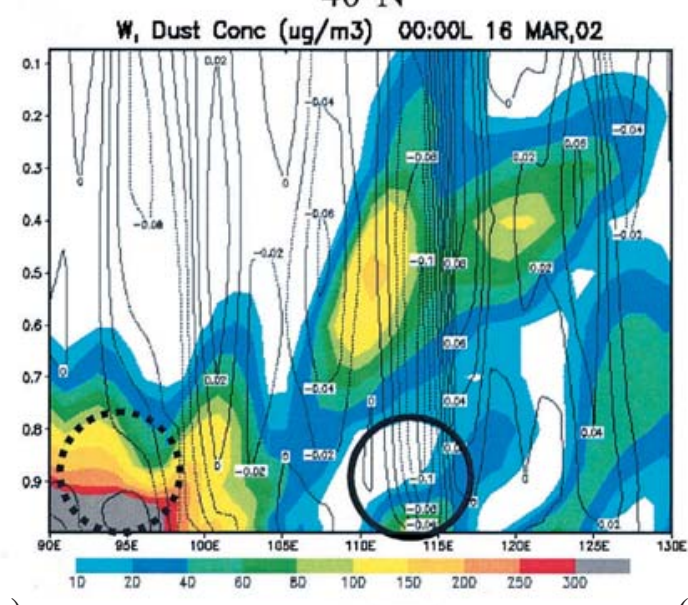

(c)

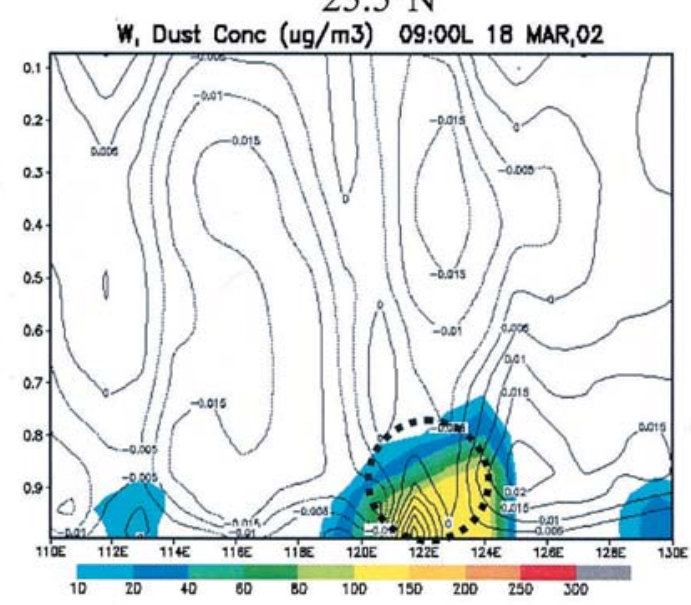

(b)

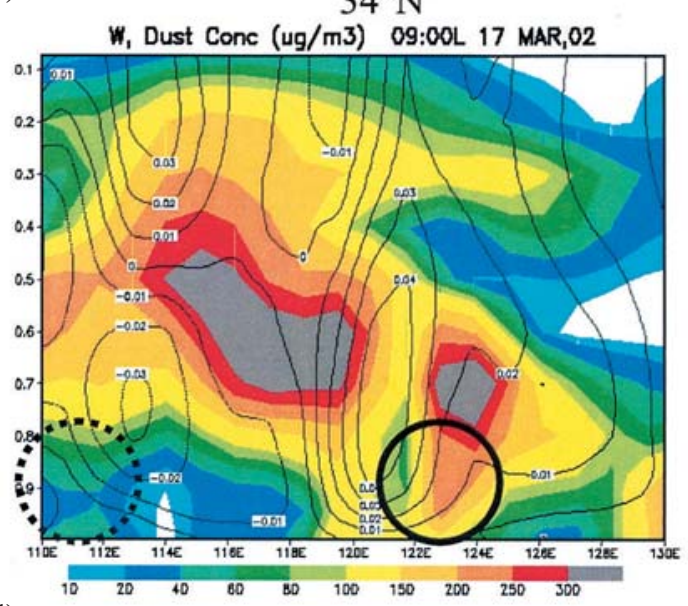

(d)

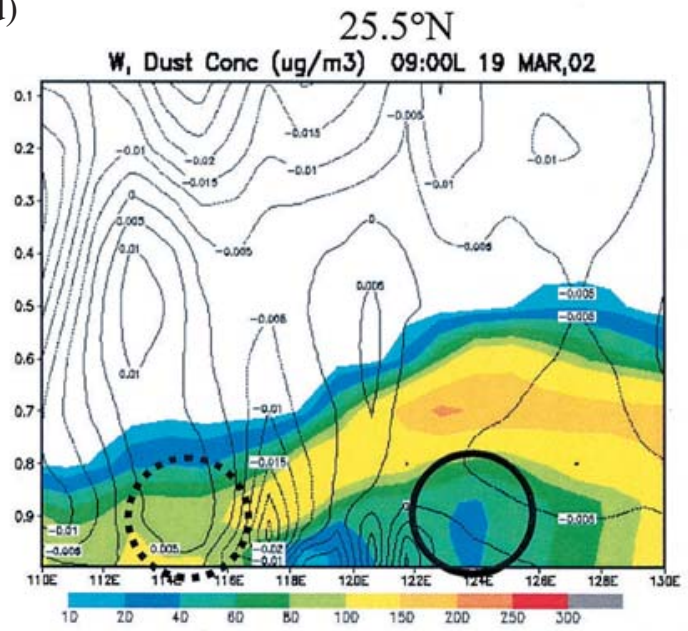

Fig. 5. Vertical distribution of dust load at different constant latitudes for the March 18 21, 2002 case. (a) Near the source region and near the initiation time; (b) Halfway through the journey, cross section taken at $34^{\circ} \mathrm{N}$; (c) Near arrival, cross section at $25.5^{\circ} \mathrm{N}$ (about $35 \mathrm{~km}$ north of the northern tip of Taiwan); (d) Second wave of dust, also at $25.5^{\circ} \mathrm{N}$. The thin lines are the vertical wind speed isopleths. The thick circles and the dotted circles are the same as those in Fig. 2. Note that for panel (a), the longitude is from $90^{\circ} \mathrm{E}$ to $130^{\circ} \mathrm{E}$, and so is different than the $110 \sim 130^{\circ} \mathrm{E}$ for the other panels. 


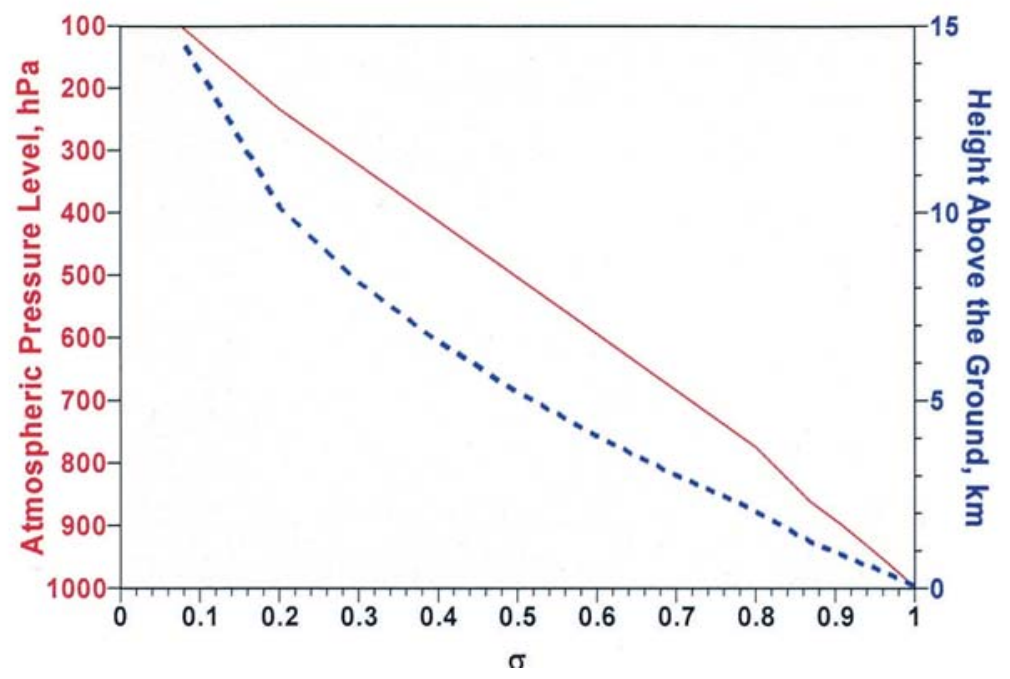

Fig. 6. Conversion of the sigma coordinate values (abscissa) to pressure (solid line, left ordinate) and height (dashed line, right ordinate) values for over the ocean near northern Taiwan.

well be more than $800 \mathrm{~m}$. Note that in Fig. 3 the second peak of $\mathrm{PM}_{10}$ obtained for the evening of March 20 at this mountain station was higher than that of the ground stations. This peak indicates that the concentration of dust could indeed be higher aloft as shown in Fig. 5d. Another way to check the thickness of the dusty air column is to perform back-trajectory analysis. As shown in Fig. 7a, the low-level $(100 \mathrm{~m})$ air, arriving over northern Taiwan on the morning of March 18, can be traced back to the source region but those above $1 \mathrm{~km}$ could not. These observations confirm that the leading edge of Parcel $\mathrm{B}$ was indeed rather shallow. Figure 7b tracks the second wave of dust (Parcel A, arriving on March 20), and demonstrates that this dust parcel was indeed thicker because the air at $100 \mathrm{~m}$ and $1 \mathrm{~km}$ both could be traced back to the source region. Note that in Fig. 7 the air traced back to the source region had an altitude of more than $4 \mathrm{~km}$ above ground level (which is a couple of kilometers above the sea level itself). These observations confirm that the dust was lifted to high levels before gradually descending to the surface.

This case may seem unique in terms of its dual dust parcel and the double peak in the hourly surface dust loading, but such behaviors were in fact rather common during 2002 and 2003. More than half of the simulated events exhibited such signatures. This case represented a swift system that moved straight toward Taiwan like a "storm trooper". The dust load stretched all the way to the surface for essentially the entire journey. The next case was rather different in this respect. 

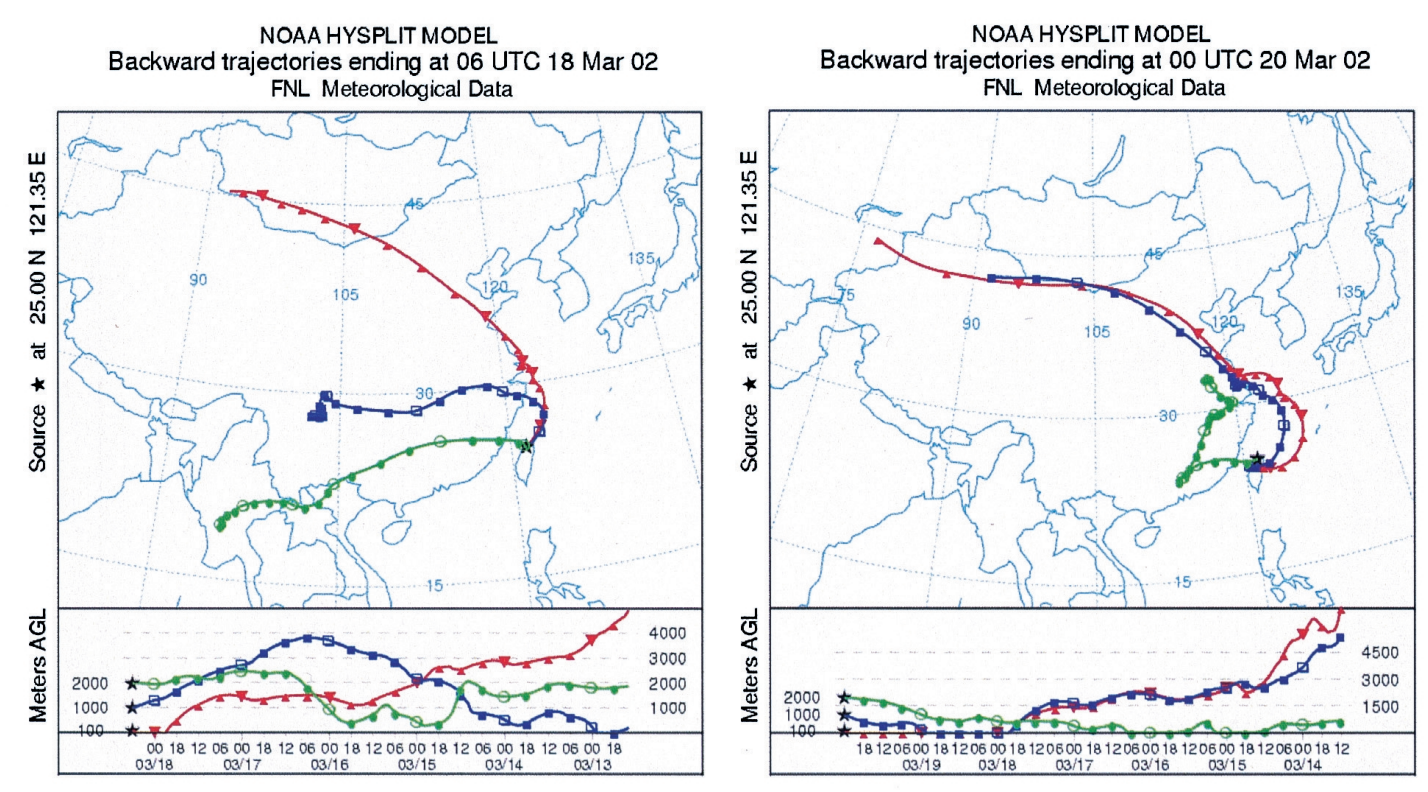

Fig. 7. Backward trajectory analysis, from the NOAA HYSPLIT model for the event of March 18 21, 2002. The left panel starts the backward tracking around the time of the first wave of dust incursion, and the right panel starts during the second wave of dust in the returning flow situation.

\subsection{Case 2: Flanking Paratrooper (March 22 27, 2003)}

In 2003, at about the same time of year (March 16) as in the previous case, a dust storm was generated in the Inner Mongolian region. The synoptic setup was similar to the previous case in that a high-low dipole resided on the surface with a deep trough aloft at $500 \mathrm{hPa}$. However, at this time the Mongolian high was weaker and the winds were not as strong, and multiple centers seemed to indicate that it was not very well organized (Figs. 8a, b). Again, a high-pressure ridge developed which extended to the southeast and later split into sub-highs. Yet, unlike the previous case, this Mongolian high did not shed its cold air in one quick burst but in pockets (several sub-highs), whose centers possibly merged later or disappeared. The high-pressure ridge did not break apart or enter the East China Sea until after March 23. In the 2002 case, the whole dust incursion event had already finished by this time.

Weak and slow systems with multiple high-pressure centers were the synoptic patterns that set up this rather different dust incursion event. Figure 9a demonstrates that multiple dusty air parcels were generated almost concurrently at the Inner Mongolian region on March 16 17. Although these parcels (mass centers enclosed by the circles) were in close proximity to each other, their fates were quite different. Parcel A (thick circle) formed a bit earlier and disap- 
(a)

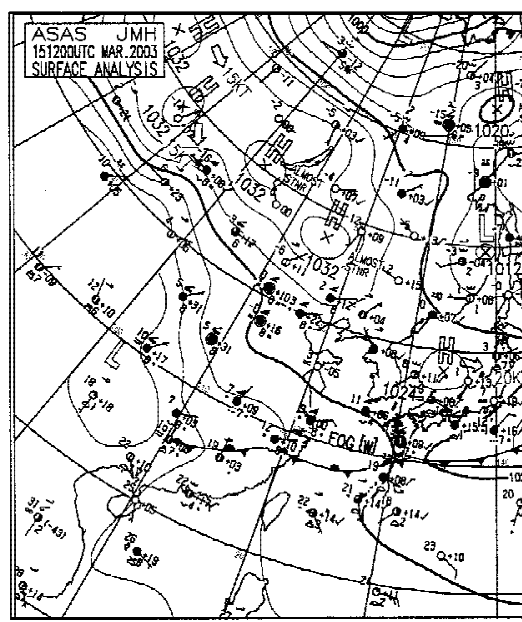

(c)

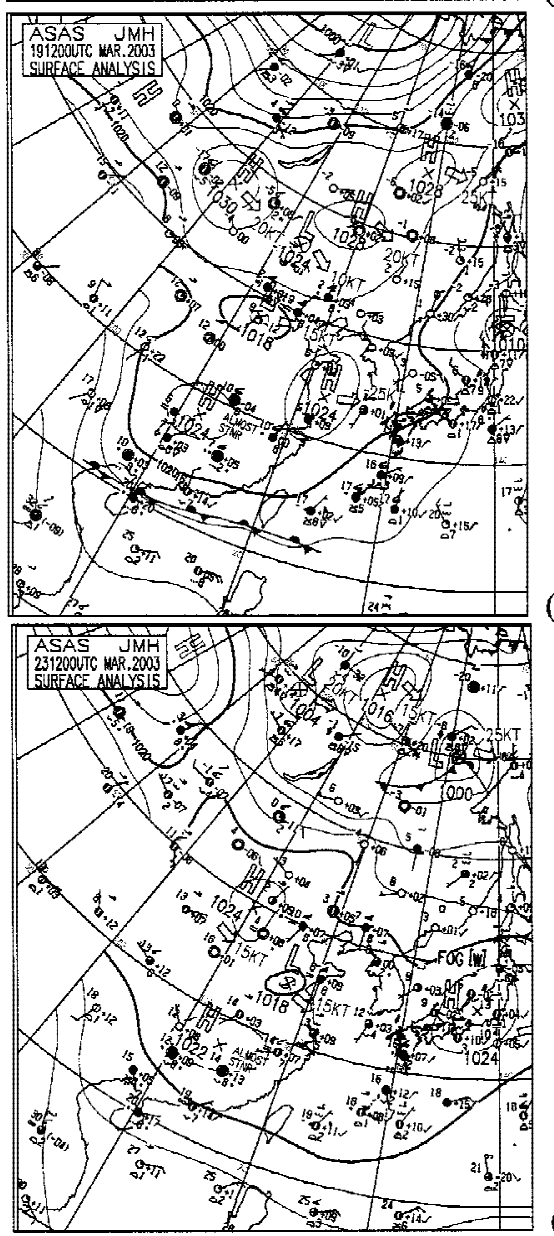

(b)

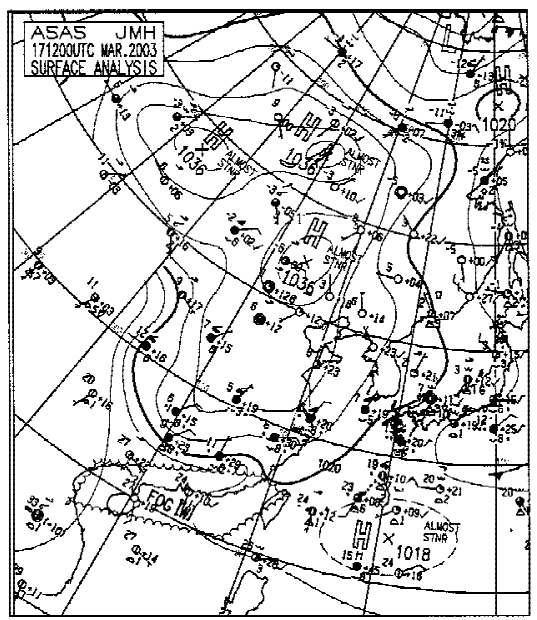

(d)
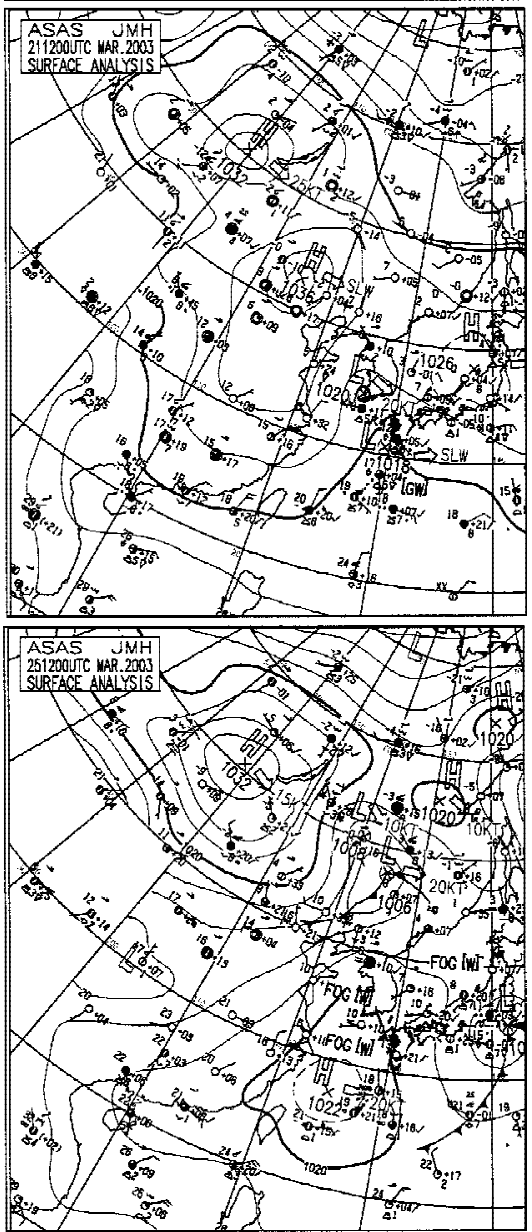

Fig. 8. Surface weather map for the dust incursion event of March 22 27, 2003. 
(a)

U, V, Surface Dust Cone $(\mathrm{ug} / \mathrm{m} 3)$ 21:00L 17 MAR,03

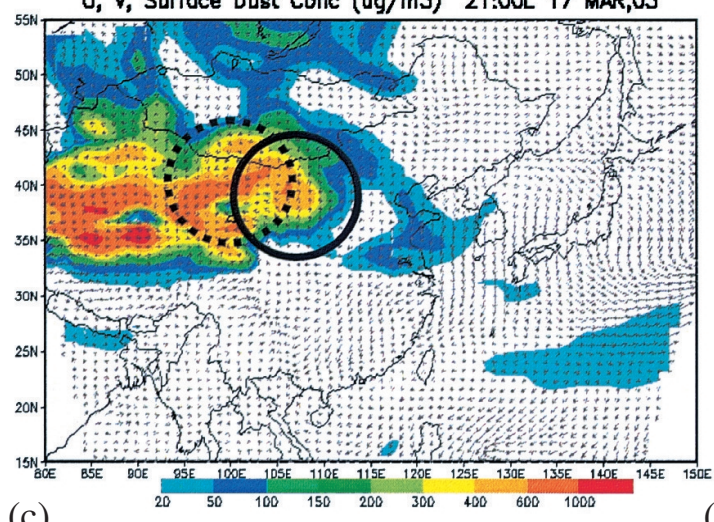

(c)

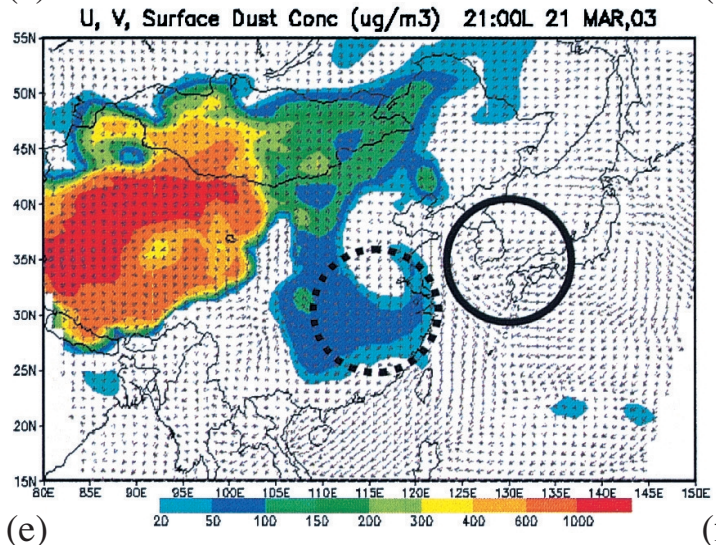

(e)

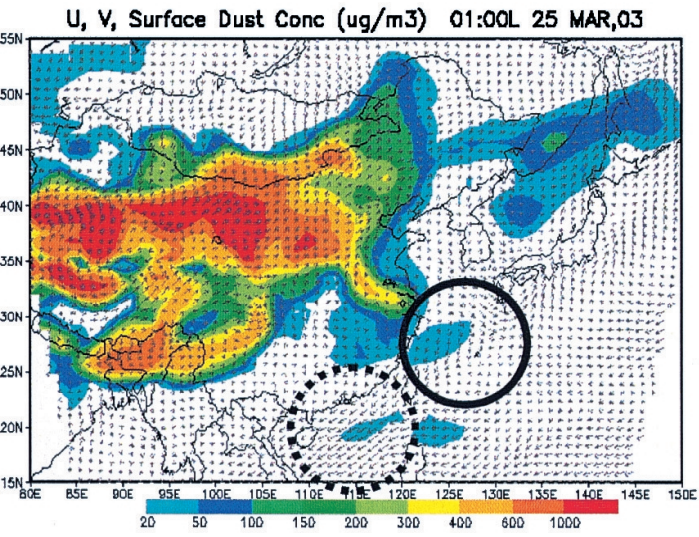

(b)

U, V, Surface Dust Conc (ug/m3) 21:00L 19 MAR,03

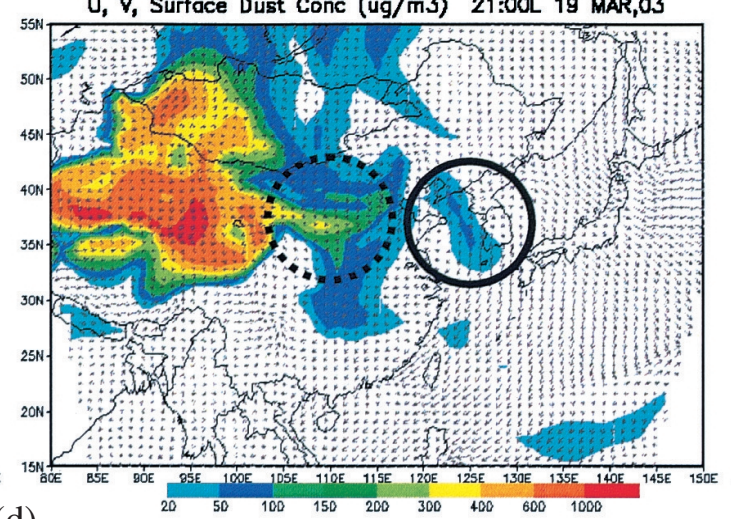

(d)

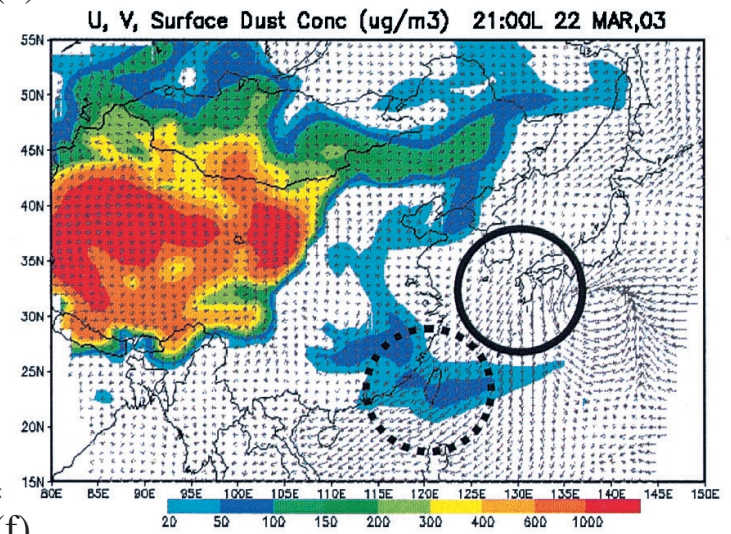

(f)

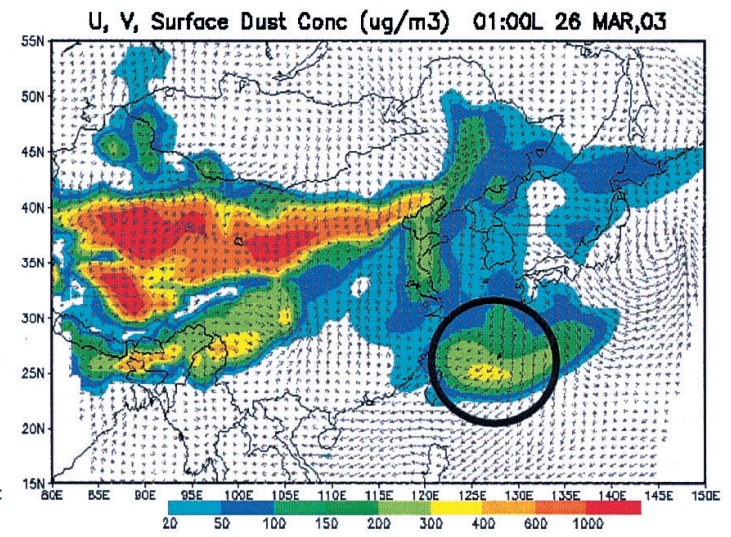

Fig. 9. Simulation of atmospheric dust loading with the TAQM/dust model for the event of March 22 26, 2003. Overlapped are the surface wind vectors. Color shades indicate the dust concentration, whereas the arrows represent the wind vector. 
peared from the surface map on the March 20 (Fig. 9c). This parcel was lofted to the middle troposphere, as demonstrated later. Parcel B (dotted circle), generated on March 17, went directly to Taiwan as in the previous case, but the journey took two to three days longer. While Parcel B was entering and vanishing in the South China Sea, a spot of dust emerged just northeast of Taiwan without prior appearance on Fig. 9e. The spot then grew to encompass a large area and approached Taiwan from the northeast to east directions to form the second wave of the dust incursion. These two waves of dust incursion (March 22 and March 25) are evident in the hourly $\mathrm{PM}_{10}$ data shown in Fig. 10. The simulation estimated the timing reasonably well, but the peak concentrations were a bit too low for the first wave and too high for the second. The large concentration gradient shown in Fig. 9f indicates that a slight shift in the horizontal distribution pattern could be responsible for the large discrepancy in the peak concentration of the second wave. The regional distribution patterns simulated by the model were generally in good agreement with several other observations, but the details will not be elaborated on here.

The later arrival on March 25 was actually the act of Parcel A, which had remained aloft

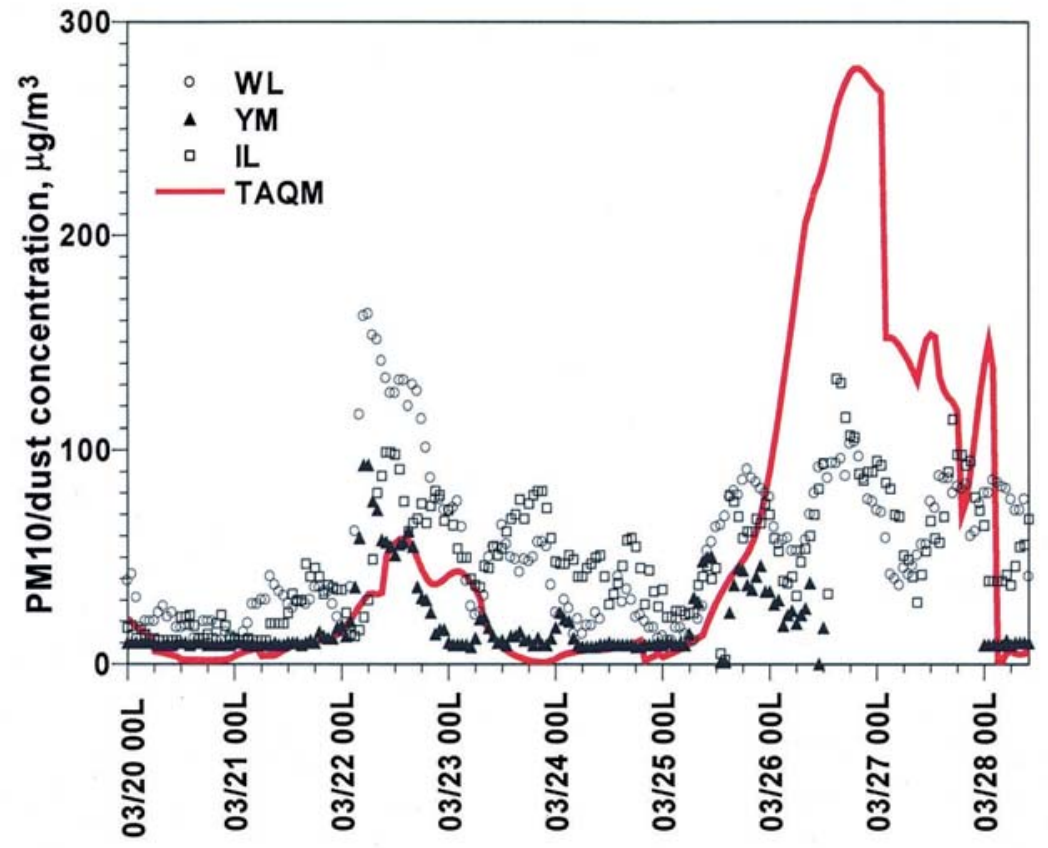

Fig.10. Hourly values of the simulated dust loading (thick lines) and the observed $\mathrm{PM}_{10}$ values (symbols). The thick solid/dashed lines are forecasts made one day prior to the dust incursion on March 22 27, 2003. The stations Wanli (WL) and I-Lan (IL) are located at the northern and northeastern coasts, respectively; whereas Yanming (YM) is an elevated station (about $800 \mathrm{~m}$ above sea level) in the northern mountain area. 
(a)

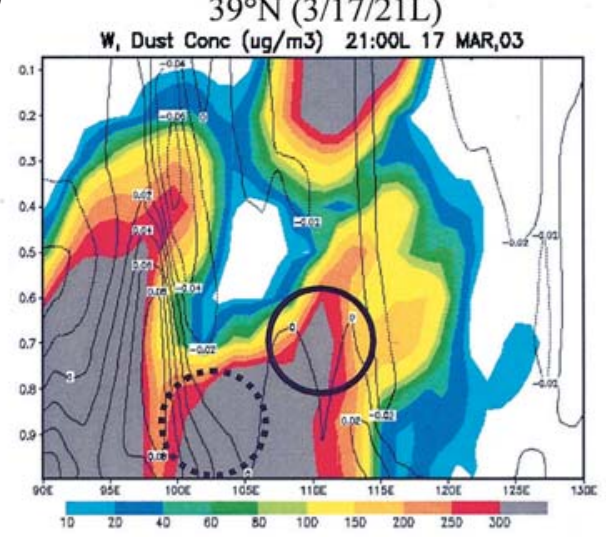

(c)

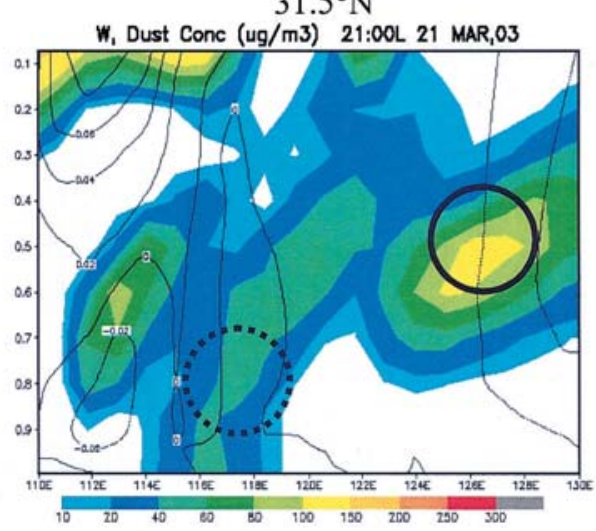

(e)

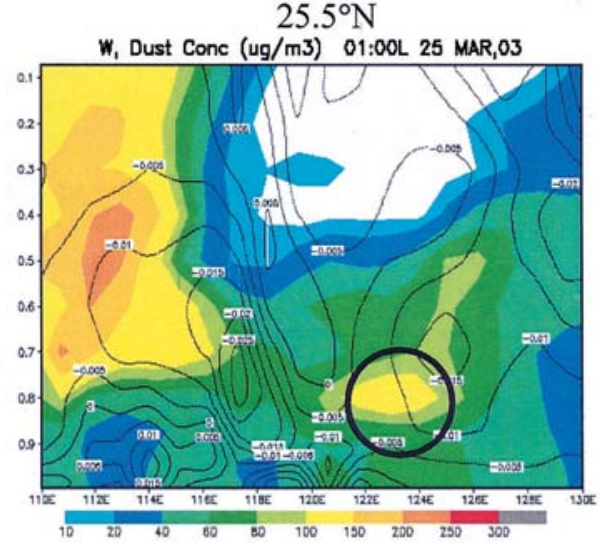

(b)

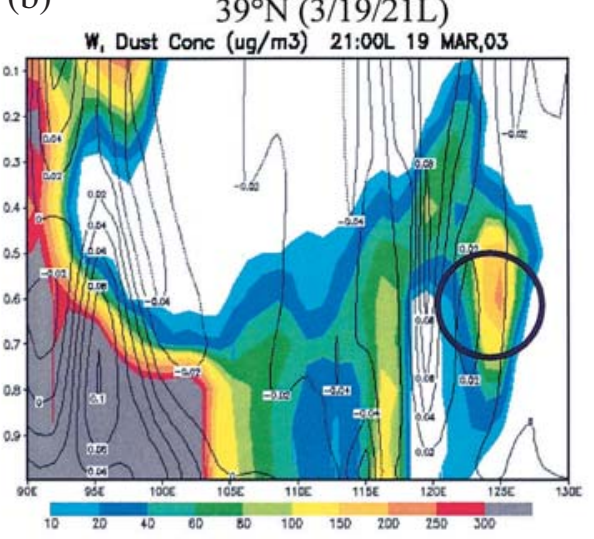

(d) $31.5^{\circ} \mathrm{N}$

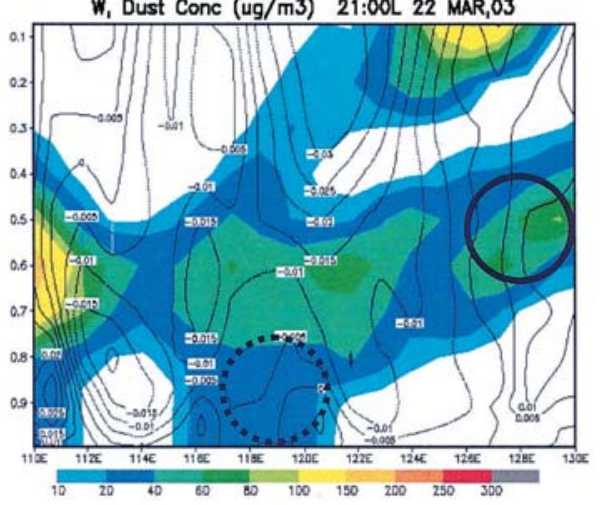

(f) $\quad 25.5^{\circ} \mathrm{N}$

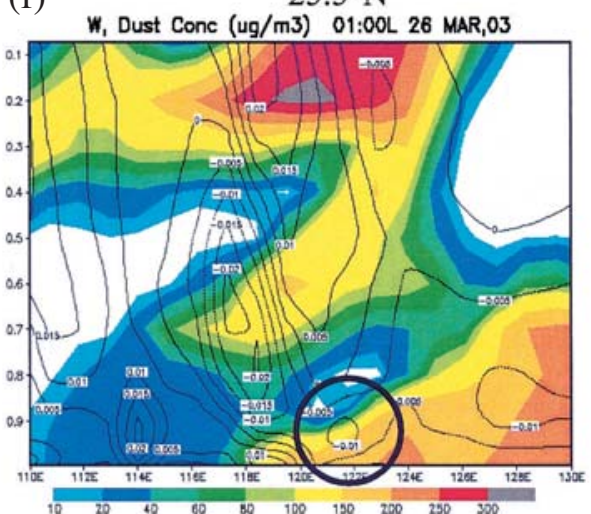

Fig. 11. Vertical distribution of dust load at different constant latitudes and different times for the March 22 26, 2003 event.

Note: the vertical cross-section at $39^{\circ} \mathrm{N}$ is taken from $90 \sim 130^{\circ} \mathrm{E}$, whereas all other at lower latitudes are from $110 \sim 130^{\circ} \mathrm{E}$. 
since the March 18. Figure 11 shows the vertical cross section at latitudes near the source $\left(39^{\circ} \mathrm{N}\right)$, halfway to Taiwan $\left(31.5^{\circ} \mathrm{N}\right)$, and just north of Taiwan $\left(25.5^{\circ} \mathrm{N}\right)$. Parcel A was initially lifted high into the midair, as demonstrated in Fig. 11a, then became completely detached from the surface after March 20, while traveling slowly to the $125^{\circ} \mathrm{E}$ longitude. At the time, this parcel resided at the northeast corner of the mid-air $(700 \mathrm{hPa}$ and $500 \mathrm{hPa})$ low-pressure system, located roughly above the Korean Peninsula. Figure 11c demonstrates that Parcel B, which maintained contact with the surface, had already crossed the $31.5^{\circ} \mathrm{N}$ latitude. Due to low wind speeds near the low-pressure system, Parcel A moved slowly southward days before and then stayed in same vicinity for quite a while, between March 21 and 23. In addition, the upward motion associated with the low-pressure system kept dust from falling to lower levels. The projected locations of Parcel A on the surface are marked with the thick circles in Figs. 9c, d. On March 23 (Fig. 11e), the low-pressure system near Korea and Japan finally weakened and moved out. Parcel A was then unleashed and descended toward the south along the eastern edge of the cutoff high that was entering the East China Sea. When the dust parcels touched down, they were located less than $100 \mathrm{~km}$ northeast of Taiwan and were brought back to Taiwan because of the returning flow. Figure $11 \mathrm{f}$ also shows that Parcel A became more and more shallow during this incursion period.

The horizontal and vertical transport routes simulated in Figs. 9 and 11 were verified by the backward trajectory analyses given in Fig. 12. For the first wave of dust (March 22), a thick layer of air (about $2 \mathrm{~km}$ high), could be traced back to the source region. The route it took to reach Taiwan was rather direct and remained mostly inland along the east coast of China. For the second wave, the dusty air flanked in toward Taiwan by high-flying over Korea and Japan. The dust then descended at the East China Sea, as demonstrated by the red curve in Fig. 12, which indicates that the surface air parcel was above $3 \mathrm{~km}$ before March 20. It is also worth noting that only the lowest layers (below $1 \mathrm{~km}$; red curve) can be traced back to the source region, as indicated by the shallow dust layer shown in Fig. 11f.

This particular case resembled the previous one in that two parcels approached Taiwan simultaneously via two different routes. As in the previous case, the dust parcels that were generated earlier actually arrived later because they detoured through the East China Sea, reaching Taiwan with the returning flow of the ocean-bound cutoff highs. However, the route taken by Parcel A was unique to the case of 2003, because its flanking airborne route, that flew high over Korea and Japan before entering the East China Sea, never touched the surface until it neared Taiwan. With traditional meteorological observation alone, it was not possible to provide advance warning of dust incursion events that took such a route. The travel time represented another major difference, between the events in 2003 and 2002. The travel time for 2003 was much longer for both waves and this was a common characteristic of most 2003 events. In this particular case, it took Parcel A about 8 days to complete the journey.

\section{GENERAL CHARACTERISTICS OF DUST TRANSPORT}

As listed in Table 1a, the study model captured 7 and 6 episodes in 2002 and 2003, respectively. Dust incursion events with peak dust concentrations less than $100 \mu \mathrm{g} \mathrm{m}^{-3}$ were 

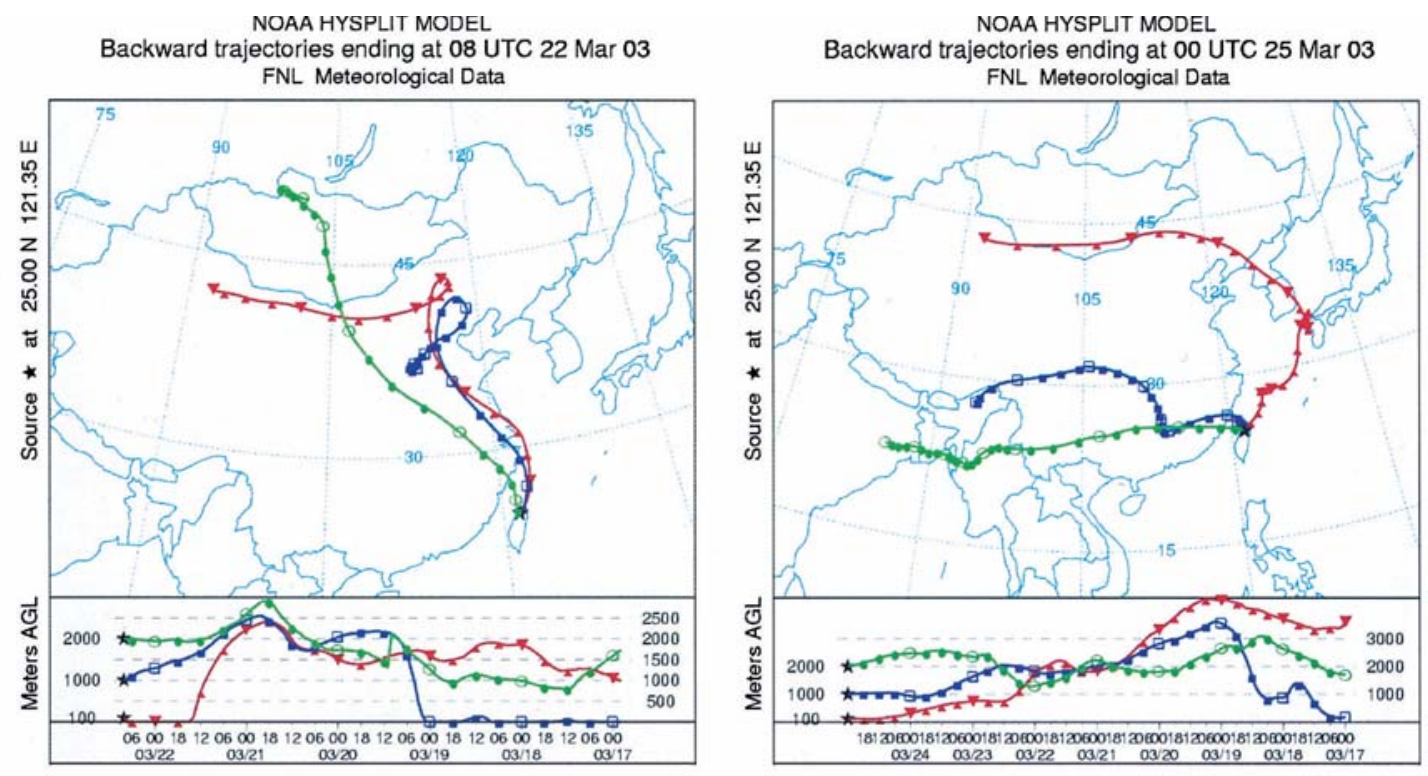

Fig. 12. Backward trajectory analysis from the NOAA HYSPLIT model for the event of March 22 27, 2003. The left panel starts the backward tracking around the time of the first wave of dust incursion, and the right panel starts during the second wave of dust in the "flanking paratrooper" situation.

not counted here because they were hard to verify with the observations. Several events possibly occurred in late winter (December to January) prior to the operation period, but they will not be discussed in this study. Table 1 also shows the time of incursion, duration, travel (from the source regions to Taiwan), and observed maximum concentration of all these episodes. To derive the travel time, the deflation time at the source region was established first, by analyzing the model results with confirmation from the dust-related weather reports. The arrival time of these events was determined by various methods, including the $\mathrm{PM}_{10}$ hourly data from Taiwan EPA's monitoring network, weather reports on dust phenomena over the surrounding regions, satellite observations, and field campaign chemical analysis data presented in various other papers (e.g., Wang et al. 2004; Lung et al. 2004; Chou et al. 2004). The travel time was obtained from the initial deflation time and arrival time and was double checked with the aid of backward trajectory analysis. This section provides a summary of the general characteristics of these events.

\subsection{Synoptic Weather Patterns}

The East Asian dust storms are generally associated with a frontal system and the Mongolian cyclonic depression (Sun et al. 2001). Strong winds that elevate yellow dust into the 
Table 1. Summarized characteristics of the dust incursion events. The incursion time is local time. Maximum concentration was taken from $\mathrm{PM}_{10}$ measurements, whereas the horizontal distribution pattern and the thickness of the dusty air column that arrived Taiwan were both determined from model results. In the "Pattern" category, A stands for "broad or patchy area" and B for "band shaped area." In the "Thickness" category, "Shallow" indicates thickness less than $2 \mathrm{~km}$, and "Thick" indicates greater than $4 \mathrm{~km}$. Since the seventh event of 2003 was not captured by simulation, so some of the characteristics were not analyzed.

(a)

\begin{tabular}{|c|c|c|c|c|c|c|}
\hline 2002 & $\begin{array}{c}\text { Incursion } \\
\text { date \& time }\end{array}$ & $\begin{array}{c}\text { Duration } \\
(\text { day })\end{array}$ & $\begin{array}{c}\text { Travel time } \\
(\text { day })\end{array}$ & $\begin{array}{c}\text { Maximum } \\
\text { concentration } \\
\left(\mu \mathrm{g} / \mathrm{m}^{3}\right)\end{array}$ & Pattern & $\begin{array}{c}\text { Dusty air } \\
\text { column } \\
\text { Thickness }\end{array}$ \\
\hline 1 & $2 / 1112 \mathrm{~L}$ & 1 & $2 \frac{1}{2}$ & 320 & A & Shallow \\
\hline 2 & $3 / 0612 \mathrm{~L}$ & 3 & $2 \frac{1}{2}$ & 140 & A,B & Thick \\
\hline 3 & $3 / 1812 \mathrm{~L}$ & $11 / 2$ & $31 / 2$ & 160 & B & Medium \\
\hline 4 & $3 / 2306 \mathrm{~L}$ & $11 / 2$ & 4 & 120 & B & Shallow \\
\hline 5 & $4 / 0900 \mathrm{~L}$ & 2 & $21 / 2$ & 200 & $\mathrm{~B}$ & Shallow \\
\hline 6 & $4 / 1712 \mathrm{~L}$ & 1 & 2 & 160 & $\mathrm{~B}$ & Shallow \\
\hline 7 & $5 / 2318 \mathrm{~L}$ & $31 / 2$ & 2 & 120 & $\mathrm{~B}$ & Shallow \\
\hline
\end{tabular}

(b)

\begin{tabular}{|c|c|c|c|c|c|c|}
\hline 2003 & $\begin{array}{c}\text { Incursion } \\
\text { date \& time }\end{array}$ & $\begin{array}{c}\text { Duration } \\
(\text { day })\end{array}$ & $\begin{array}{c}\text { Travel time } \\
(\text { day })\end{array}$ & $\begin{array}{c}\text { Maximum } \\
\text { concentration } \\
\left(\mu \mathrm{g} / \mathrm{m}^{3}\right)\end{array}$ & Pattern & $\begin{array}{c}\text { Dusty air } \\
\text { column } \\
\text { Thickness }\end{array}$ \\
\hline 1 & $2 / 1800 \mathrm{~L}$ & 3 & 4 & 80 & $\mathrm{~A}$ & Shallow \\
\hline 2 & $2 / 2506 \mathrm{~L}$ & $61 / 2$ & 3 & 100 & $\mathrm{~A}$ & Shallow \\
\hline 3 & $3 / 0721 \mathrm{~L}$ & $31 / 2$ & 2 & 100 & $\mathrm{~A}$ & Medium \\
\hline 4 & $3 / 2201 \mathrm{~L}$ & 2 & 5 & 160 & $\mathrm{~B}$ & Thick \\
\hline 5 & $3 / 2507 \mathrm{~L}$ & $31 / 2$ & $71 / 2$ & 110 & $\mathrm{~B}$ & Medium \\
\hline 6 & $5 / 2007 \mathrm{~L}$ & $41 / 2$ & $51 / 2$ & 110 & $\mathrm{~A}$ & Medium \\
\hline 7 & $5 / 3006 \mathrm{~L}$ & $(3)$ & $*$ & $(120)$ & $*$ & $*$ \\
\hline
\end{tabular}


atmosphere occur where there are large pressure gradients between the Mongolian high-low dipole systems. Above the dipole system, a deep trough at $500 \mathrm{hPa}$ is also a crucial factor in generating the dust storms. Subsequent transport of the yellow dust is then controlled by the cold air outbreak from the Mongolian high. Very often a sub-high system would split from the main Mongolian high and move southeastward into the East China Sea to form a cutoff high. This feature is crucial to the transport of yellow dust to Taiwan. Liu and Hsiao (2004) found that for the dust deflation events, which influenced Taiwan, the polar high extension covered an area to the south of the Yellow River; whereas for those that did not influence Taiwan the coverage was limited to the north of the Yellow River. Their findings were in accordance with events described in this study. The dust incursion events over Taiwan usually occurred after the passage of a cold front, which was pushed forward by the ocean-bound cutoff high. In addition, the returning flow of the cutoff high frequently brought in a second wave of dust from the east as demonstrated in the previous section.

Dust transport patterns in 2003 were different from those in 2002 in some respects. The main reason for these differences was a weaker Mongolian high-low dipole in 2003. In Figs. $13 \mathrm{a}, \mathrm{b}$, the 10 -year average geopotential heights at $1000 \mathrm{hPa}$ (extrapolated where the ground elevation was high) indicate a prevalent high-pressure system sitting at northeastern Mongolia during winter, with a ridge extending toward the southeast into the northwestern Pacific. In spring, this high-pressure center becomes weaker and prevalent sub-centers appear along the winter ridge, indicating frequent formation of cutoff highs. Furthermore, since a low-pressure core appeared north of Japan, just off the map, the east-west pressure gradient over the Mongolian region is not necessarily weaker in spring than in winter.

Looking at the geopotential height anomalies is another way to manifest the synoptic setups. In winter and spring 2002, the geopotential heights decreased over almost the entire domain, with the allobaric center located north of the Tibet Plateau in winter and at northern Mongolia in spring (Figs. 13c, d). During winter 2003, the Mongolian high became even weaker, as demonstrated by the greater negative anomalies shown in Fig. 13e. A significant reduction in geopotential heights also occurred along the high pressure ridge during spring, particularly in 2003 (Figs. 13d, f). When the anomalies became less significant and even turned to positive values toward the east, this indicated that the Mongolian low had also weakened in 2003 (Figs. 13e, f). Therefore, even though the strength of Mongolian high does not change much, the diminishing east-west pressure gradient indicates a weaker synoptic-scale circulation in the spring of 2003. As mentioned earlier, a strong wind associated with a strong pressure gradient over the dust source region is a key factor to the occurrence of dust storms. So it is plausible that the less frequent dust invasion over Taiwan in 2003 is associated with a fading Mongolian highlow dipole system, although more detailed analysis may be required to confirm this postulation.

\subsection{Source Location and Transport Route}

The source locations of yellow dust that reached Taiwan in 2002 and 2003 were analyzed from the simulation results. Most of the results agree well with the HYSPLIT backward trajectory analysis as well as weather reports on dust phenomena. As shown in Fig. 14, the main source regions can be located within the Gobi desert of southern Mongolia, Ordos Desert in 
(a) 10yr DJF sfc Geopotential Height Average

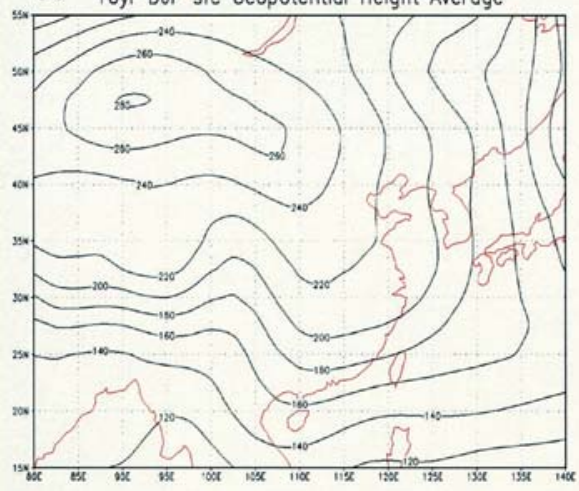

(c) 2002 DJF sfc Geopotential Height Anomaly

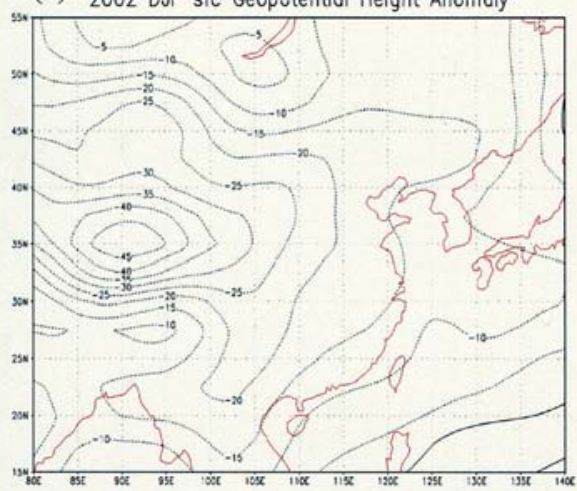

(e) 2003 DJF sfc Geopotential Height Anomoly

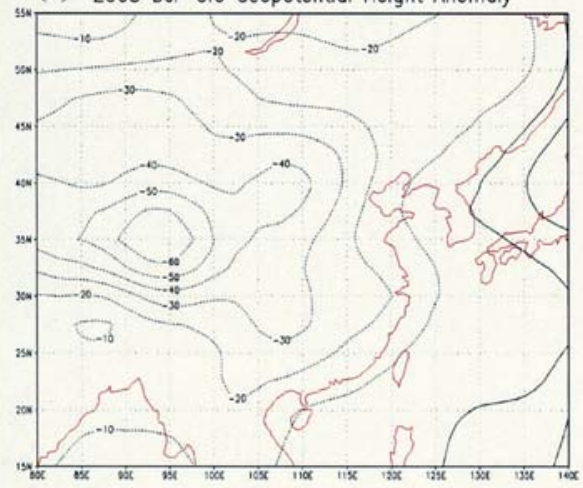

(b) 10yr MAM sfc Geopotential Height Average

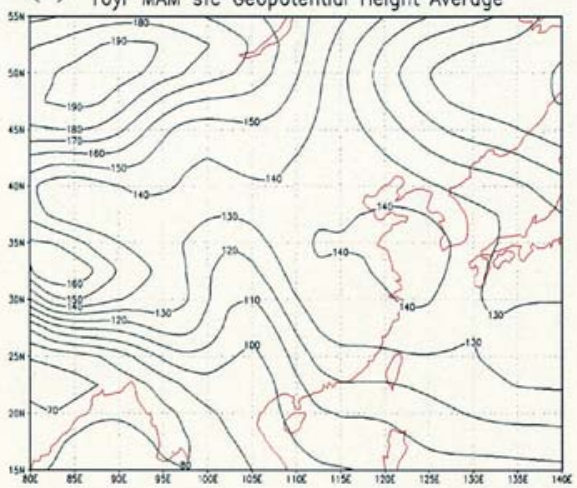

(d) 2002 MAM sfc Geopotential Height Anomaly

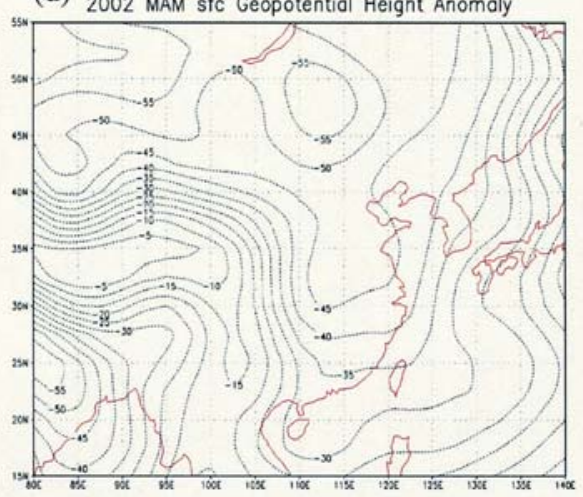

(f) 2003 MAM sfc Geopotential Height Anomaly

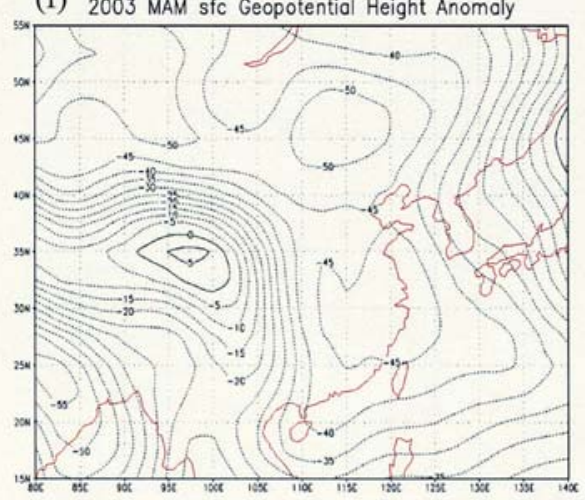

Fig. 13. Geopotential heights and anomalies at the $1000 \mathrm{hPa}$ level. Top: 10-year (1991 2000) average; Middle: anomalies in 2002; Bottom: anomalies in 2003. The left panels are for winter (December of previous year to February) and the right panels are for spring (March to May). Solid and dashed lines indicate positive and negative values, respectively. These plots are generated from ECWMF reanalysis data. 


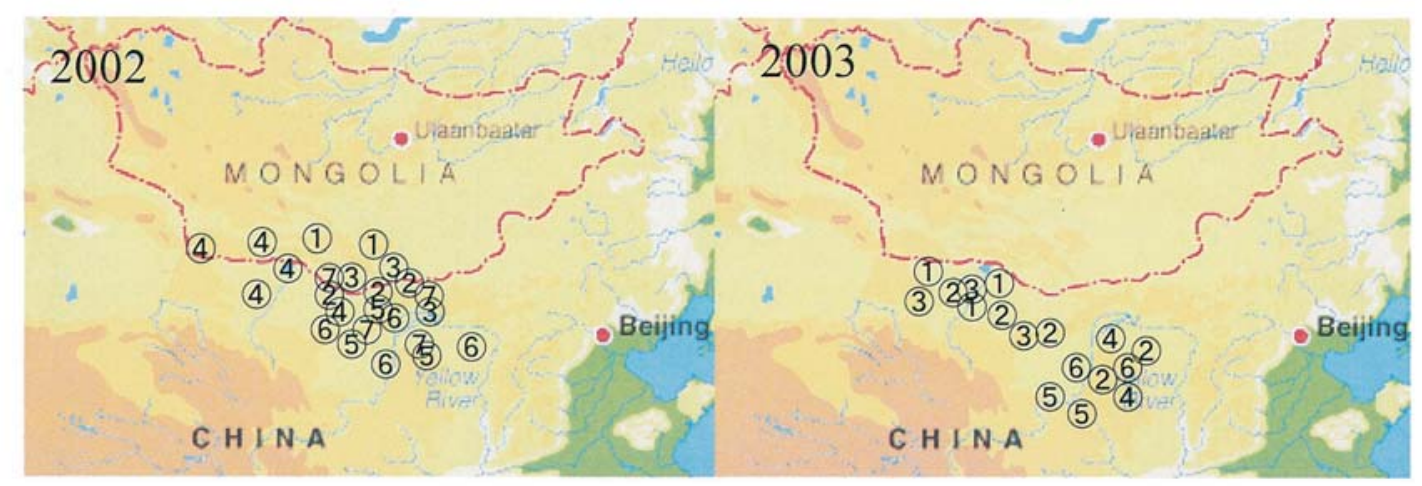

Fig. 14. Source locations of the episodes of dust incursion over Taiwan during 2002 and 2003. The circled numbers refer to the occurring sequence of episodes listed in Table 1, and they are shown repeatedly to roughly mark the area size.

Inner Mongolia or areas of the Loess Plateau. Simulated dust storms that originated from the Taklamakan desert (in Xinjiang Uygur Autonomous Region) normally do not bring dust toward southern China and Taiwan but rather eastward, at high elevations, to Japan and Korea. This result was in accordance with findings of Sun et al. (2001). Note that in 2003 none of the episodes seemed to originate from the Gobi desert, and this might reflect the different climate patterns between 2002 and 2003. This study demonstrated that the Mongolian high-low dipole was weaker in 2003 (Fig. 13). Higher snow cover possibly inhibited the deflation of dust, but the signals were not clear in Fig. 15, except during the winter of 2003 (December 2002 February 2003) when the anomalies were indeed higher over the whole source regions mentioned previously.

Although no definitive conclusion can be drawn from a few episodes, the source location seems to possess a seasonal pattern. In early spring, the source location lies in Southern Mongolia/Inner Mongolia then appears to shift southward to the Loess Plateau in late spring. In fact, all episodes that occurred during April and May of these two years originated from the Loess Plateau.

\subsection{Transport Spatial Patterns}

Observations can only provide limited information on the temporal and spatial structures of the dust storms. Synoptic meteorological observations and satellite observations both lack resolution for the vertical structure of a dust layer, and very often cannot provide complete horizontal coverage either (the former are void over the ocean and remote areas, whereas the latter are often obscured by clouds). Lidar observations, on the other hand, may provide some details of the vertical structure but unfortunately are not generally implemented to enhance spatial coverage. As a result, few studies have provided a three-dimensional view of the defla- 
NCEP anomalies snow cover Dec2001 Feb2002

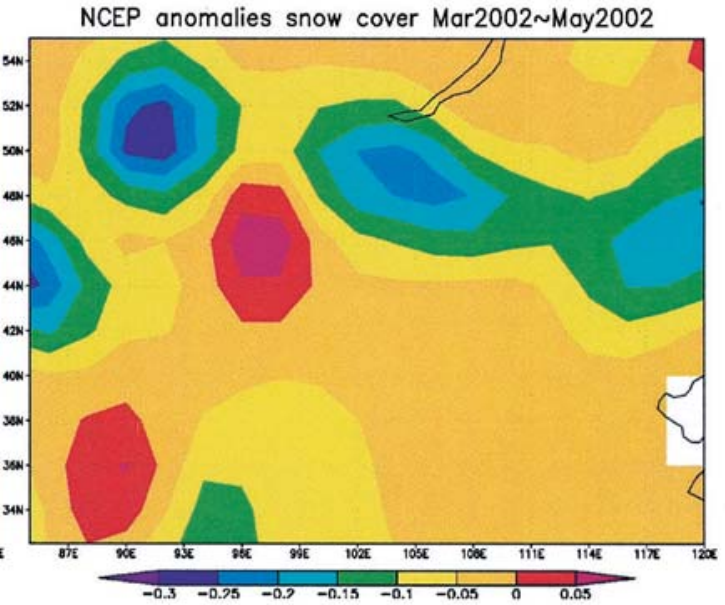

NCEP anomalies snow cover Dec2002 Feb2003

NCEP anomalies snow cover Mar2003 May2003
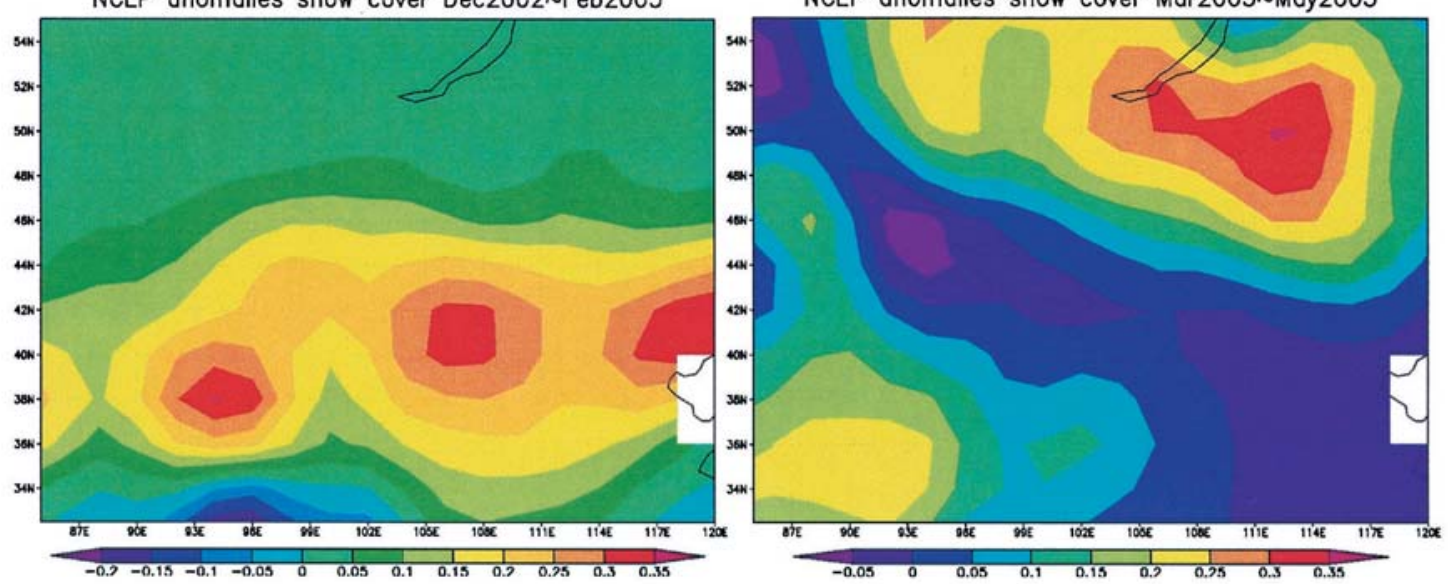

Fig. 15. Anomalies in snow cover during the winter and spring seasons of 2002 and 2003. The domain is roughly the same as that in Fig. 14. Notice the difference in the color scales.

tion and transport processes of dust storms. Numerical simulations, such as those demonstrated in this study, may turn out to be a good visualization aide to better understanding the transport pathways of dust incursion events. The following describes the main transport pattern according to model results.

In simulations, the dusty air mass approached Taiwan either as a broad (and sometimes patchy) area that overwhelms a large portion of Eastern China, or as an elongated band (Table 1b). Figure 16 schematically demonstrates the formation of the banded transport pattern according to time-laps animation of the model results. The dusty air mass originally appeared as a rotund region where the strong wind region aligned with the surface dust source (Fig. 16a). It then 
gradually stretched into a band shape partly due to a sustained wind blown from the source region, and partly due to deformation of the Mongolian cold air mass that gushes southeastward behind a cold front (Figs. 16b, c). Such band-shaped dust parcels are usually seen trailing behind a cold front by a distance of a few hundred kilometers. How far this band trailed behind the front depended on the original spot of dust deflation, which was generally located at the greatest pressure gradient (and thus strong winds) between the centers of the Mongolian high and Mongolian depression system, as well as the amount of precipitation washout from the large area behind the front. As the high pressure ridge extended toward the Pacific Ocean and cutoff from the main Mongolian High, the southern edge of the cold surge gradually lost strength and slowed down, while the northern cold air at Central China pushed the eastern air mass toward the Yellow Sea, thereby stretching the dusty air even further (Figs. 16c, d). The anti-cyclonic circulation of the cutoff high later caused the dust that entered the Pacific to move back toward the land along with the "returning flow" (Fig. 16d).

Episodes that came with shallow dusty air mass (within about 2 kilometers from the surface) were usually associated with belt-shaped systems. In contrast, the broad-area pattern episodes often came with a dusty column that could extend to the $500 \mathrm{hPa}$ level over Taiwan. The 2002 dust often took the surface route and approached Taiwan from the northern directions. In 2003 however, the dust often reached Taiwan via a curved-in route. This dust was first elevated to mid troposphere near the source, then carried eastward by the westerly wind field. The westerly however was not strong enough to carry it across the Pacific Ocean, so the dust gradually descended while traveling with the returning flow of the split high that entered the East China Sea and finally reached Taiwan from the east or northeast.

\subsection{Travel Time and Duration}

The duration of the 2002 dust incursions over Taiwan was usually less than 2 days except for the May 23 episode that lasted for 90 hours and the March 6 episode that lasted for about 70 hours. The long duration was caused by the unique setup of the "returning flow" pattern such that after the arrival of the first wave of dust following a frontal passage, a second and even a third wave of dust were brought to Taiwan from the east. Events associated with such a returning flow are generally associated with extended duration.

Dust events in 2003 were characterized by their longer transport time and weaker strength. As discussed earlier, these characteristics could be attributed to the weaker cold air outbreaks, which caused the wind speed and the movement of the weather systems to slow, more than in the previous year. As a result, most of the dust events took more than 3 days to reach Taiwan, whereas those in 2002 generally took less than 3 days. Note that these transport times were estimated from the simulation results, but verified with the HYSPLIT trajectory analysis and weather reports on dust phenomena near the source region.

\subsection{Seasonal Dust Distribution}

Dust plays a crucial role in physical and chemical processes in the atmosphere and in marine ecosystems. However due to limited observations, their spatial distributions are not 
very well known, which mitigates an understanding of their potential influences. Satellite measurements provide regional distributions of aerosols, but it is not easy to separate dust from other aerosol particles in the data. In addition, the satellite does not resolve vertical
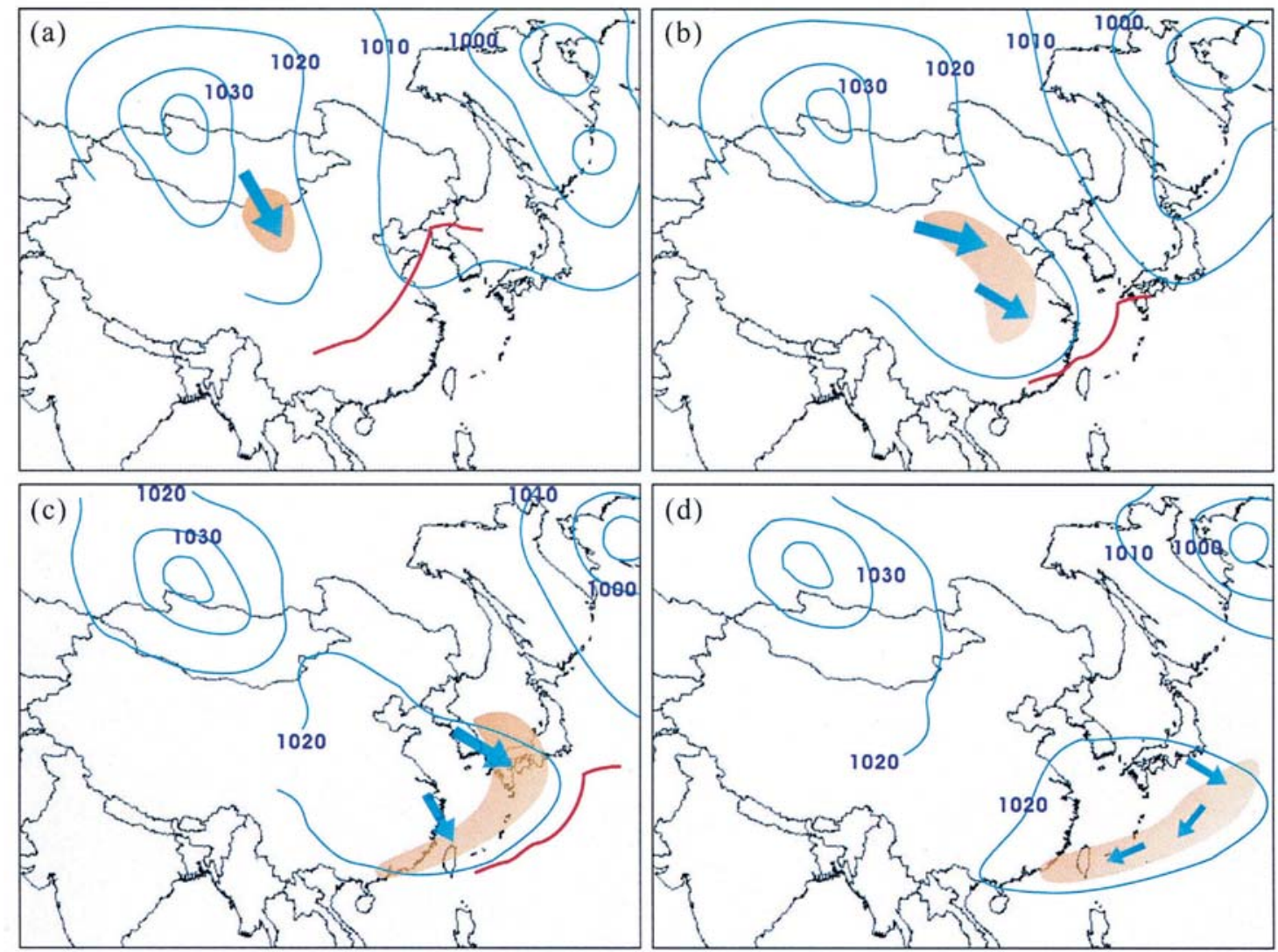

Fig. 16. Schematic demonstration of the formation of a typical band-shaped dusty air mass during transport. The dusty area (at the surface) is shaded light brown; the blue arrows indicate the strength and direction of the cold air surge that carries the dust; light-blue contours show the pressure field (in $\mathrm{hPa}$ ), and the red curve indicates a frontal system. (a) Initiation of dust deflation under strong winds; (b) The dusty air mass moves southeastward and stretches into a band due to transport and deformation of the high pressure ridge; (c) The ridge starts to separate from the main Mongolian high, and the elongated dust band in the leading edge of the continental cold air rushes toward the Pacific rim behind a cold front; (d) The returning flow of the cutoff high bringing back dusty air over the Pacific toward Taiwan. 
structures. In the following, a summary of the simulated spatial characteristics of atmospheric dust provides information relevant to scientific communities that interested in dust phenomenon. The bulk features for 2002 were generally similar to those in 2003 , so only the data for 2003 is displayed for discussion.

Figure 17 shows the spring-mean concentration of dust at four vertical levels over East Asia for 2003. From the surface plot (Fig. 17a), the dust was obviously more concentrated near the source regions (Taklamakan desert, Loess Plateau, Inner Mongolia, etc.), where the spring mean concentration reached several hundred $\mu \mathrm{g} \mathrm{m}^{-3}$. Since the dust entering the oceans is important to marine primary production, and could have significant implications for the $\mathrm{CO}_{2}$ budget (Martine 1990; Young et al. 1991), an examination of situations over the oceans is warranted. As Fig. 17a demonstrates surface dust concentration decreases rapidly toward the oceans. Nevertheless, seasonal dust concentration was well above $10 \mu \mathrm{g} \mathrm{m}^{-3}$ over most of the East China Sea, as well as parts of the western North Pacific and South China Sea. A high concentration tongue that extended into the East China Sea and the Pacific Ocean was also noted. This tongue was associated with the split high system and the "returning flow" pattern, discussed in Section 4.3 (Fig. 16). A monthly data check indicated that this high concentration tongue was attributable almost entirely to the events in March. However, this "tongue" feature is not obvious in 2002, indicating less frequent split high features for that period. Over the entire domain, at least $1 \mu \mathrm{g} \mathrm{m}^{-3}$ of dust can be found.

A gradual shift of patterns occurred toward higher levels. At the $\sigma=0.8$ level (around $850 \mathrm{hPa}$ ), the patterns were rather similar to those at the surface, but the tongue that extended into the East China Sea was noted to possess a higher dust concentration than at the surface (Fig. 17b). In addition, the westerly component of the wind fields was stronger, so the split high and "returning flow" features on the surface seemed to be rather shallow. At even higher levels (Figs. 17c, d), the high concentration zone near Inner Mongolia and the Loess Plateau gradually disappeared and only the one over the Taklamakan desert remained. This indicates that dust from Inner Mongolia and the Loess Plateau tended to stay at the lower troposphere, whereas dust from the Taklamakan desert was more likely to enter the upper troposphere and enter the westerly. This finding is consistent with the analysis of Sun et al. (2001). As a result, there was more dust aloft $\left(\sim 60 \mu \mathrm{g} \mathrm{m}^{-3}\right)$ than near the surface $\left(\sim 20 \mu \mathrm{g} \mathrm{m}^{-3}\right)$ over the East China Sea and the western North Pacific. It is worth noting that there was seasonal upper-air trough aligned over the western Pacific Rim, which indicates the westerly bought the elevated dust firstly southward to the lower latitudes, and then veered northward once it had passed over the Pacific.

Figure 18 shows the vertical cross sections of mean dust concentration over two regions. The first region (longitudinal profile at $130^{\circ} \mathrm{E}$; Fig. 18a) was selected to show how much dust might enter the westerly then transported to the western North Pacific. About $10 \sim 20 \mu \mathrm{g} \mathrm{m}^{-3}$ of dust was transported to just above the surface of the western North Pacific, with the highest concentrations located at the Japan Sea. In the upper air, about 30 50 $\mu \mathrm{g} \mathrm{m}^{-3}$ of dust entered the westerly, and the concentration was higher at the southern latitudes. It seems that significant amounts of yellow dust may have been transported toward the Central Pacific. Since this dust has relatively low fall speeds, it is quite possible that it can travel to North America and perhaps even further by riding with the westerly, as pointed out by Merrill et al. (1989) and 
Wilkening et al. (2000). However, what fraction of the dust readily falls into the Pacific to feed the plankton and how much actually travels further requires global-scale analysis.

The second region is over the South China Sea and the Philippine Sea. Here, dust concentration was lower at the surface and decreased toward the east. In fact, the entire surface region to the west of $110^{\circ} \mathrm{E}$ contained only $5 \sim 10 \mu \mathrm{g} \mathrm{m}^{-3}$ of dust during this most frequent of duststorm seasons. According to the mean wind field, it is obvious that the surface airflow over these oceans was mainly controlled by the clean tropical easterly, and the continental cold air with high dust burden visited less frequently here than to the East China Sea. In the air aloft,

(a)

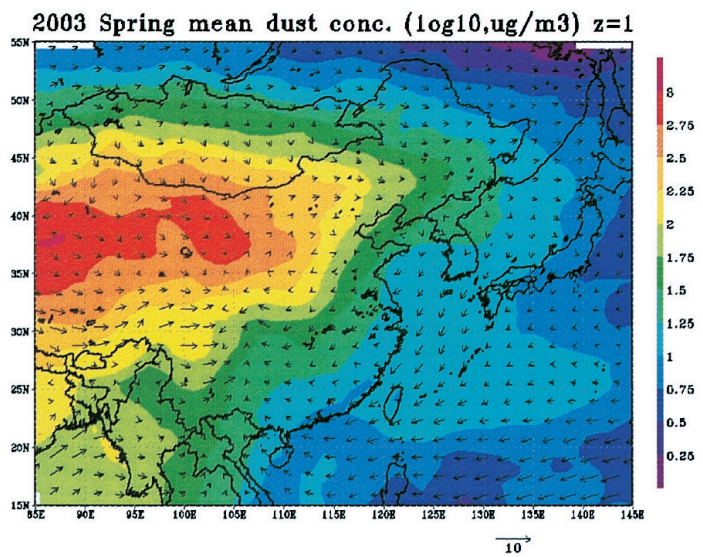

(c)

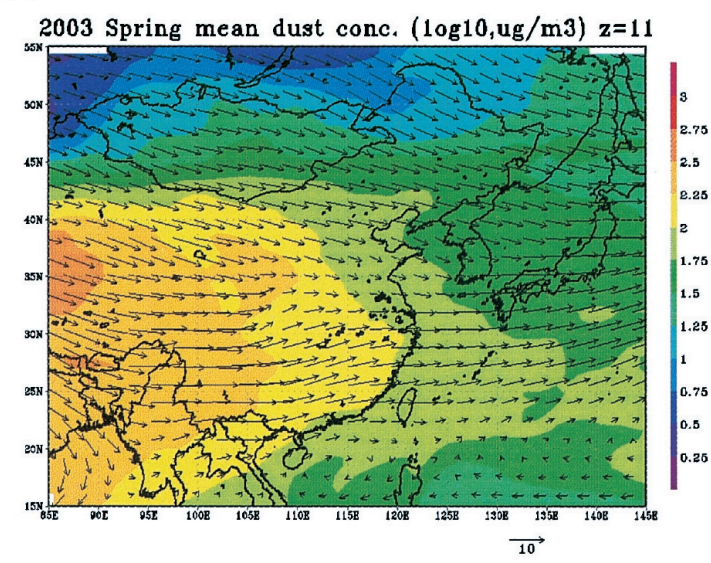

(b)

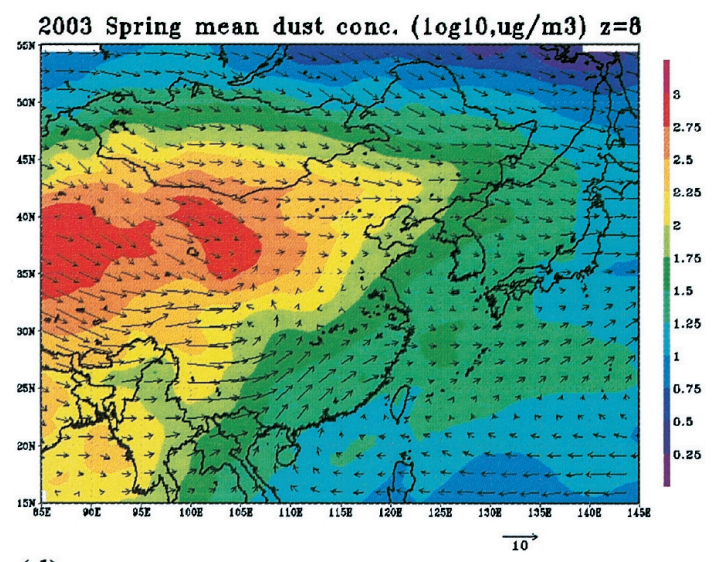

(d)

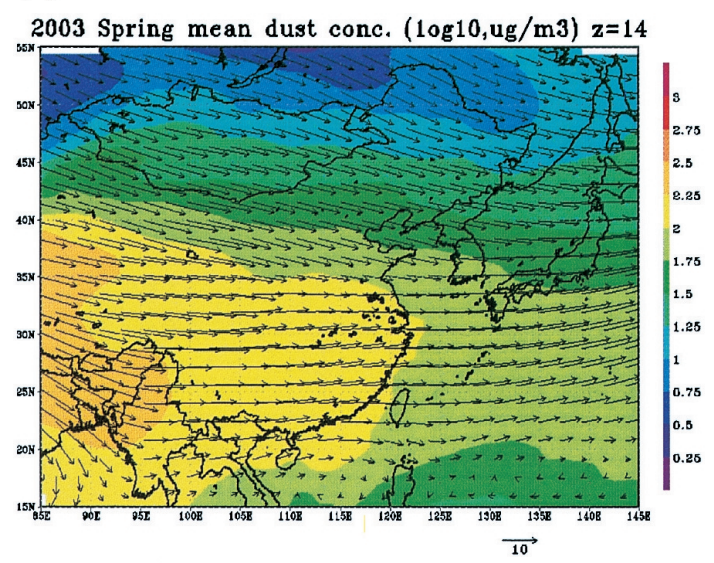

Fig. 17. Mean dust concentration over East Asia at four $\sigma$ levels during spring 2003. (a) $\sigma=0.998$, near surface; (b) $\sigma=0.799$, near the $850 \mathrm{hPa}$ level; (c) $\sigma=0.5$, near the $700 \mathrm{hPa}$ level; (d) $\sigma=0.2$, near the $400 \mathrm{hPa}$ level. The color scheme is in $\log _{10}$ scale. Vectors that overlaid are the mean horizontal winds. 
(a)

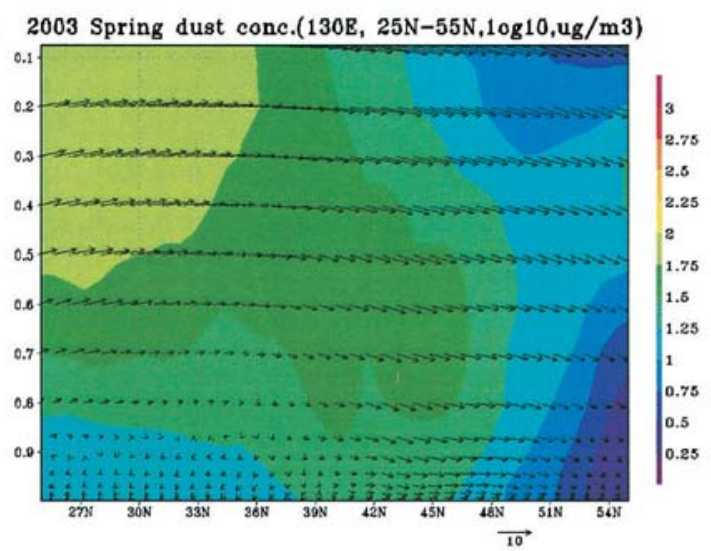

(b)

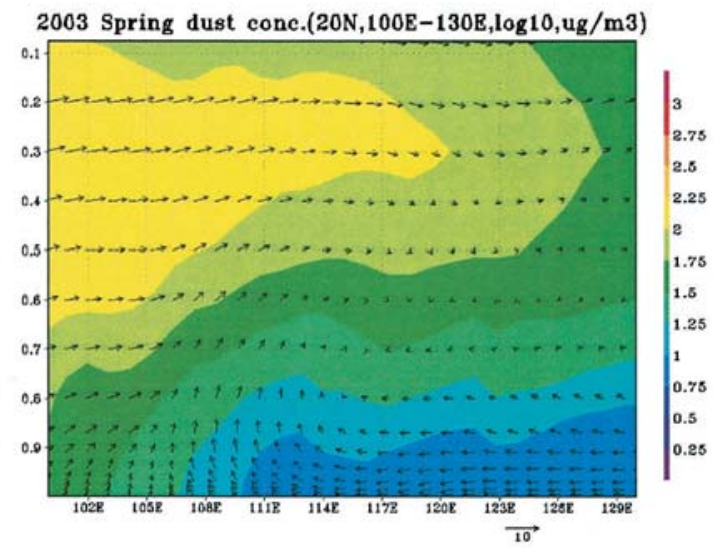

Fig. 18. Vertical profile of mean dust concentration during the spring of 2003. (a) Latitudinal profile at $130^{\circ} \mathrm{E}$; crossing the western North Pacific; (b) Longitudinal profile at $15^{\circ} \mathrm{N}$; crossing the South China Sea and Philippine Sea. The color scheme is in $\log _{10}$ scale. Vectors that overlaid are the mean horizontal winds.

dust concentration was much higher, reaching over $100 \mu \mathrm{g} \mathrm{m}^{-3}$ west of the $120^{\circ} \mathrm{E}$ longitude. This upper-air dust obviously originated from the Taklamakan desert as shown in Figs. 17c, d and was brought here by the westerly. Due to the limitation of the model domain size, it was difficult to tell whether a significant amount of Asian dust was transportable to the equatorial region or even the southern hemisphere.

\section{EVALUATION OF MODEL PERFORMANCE}

The operational performances of the yellow dust forecast models are evaluated according to the standards given in Table 2 . Since the absolute score from this arbitrary scoring system might not be very meaningful, an attempt to obtain scores for contrast from two other similar models (NAAPS and CFORS) was undertaken. The CFORS model is based on a three-dimensional on-line regional scale chemical transport model fully coupled with RAMS (Regional Atmospheric Modeling System). It applies a 12-bin mineral dust scheme with emission strength expressed as a function of surface friction velocity. The horizontal grid resolution was $80 \mathrm{~km}$, whereas the vertical domain was divided into 23 layers with the top level located at $20 \mathrm{~km}$. Note that CFORS is not really an operational model but rather a research mode model. The NAAPS global aerosol model uses global meteorological fields from the Navy Operational Global Atmospheric Prediction System analyses and forecasts on $1^{\circ} \times 1^{\circ}$ grids, and 24 vertical levels reaching $100 \mathrm{hPa}$. Dust emission occurred whenever the friction velocity exceeded a threshold value and both snow depth and surface moisture were was less than the critical values. The size-dependent emission flux was taken from Westphal et. al. (1988) and scaled to 
Table 2. Scoring standards for the evaluation of model performance. A maximum score of 4 points is given when the difference between modeled and observed arrival times (as well as durations) is within 3 hours, or when the difference in maximum concentration is within $50 \mu \mathrm{g} \mathrm{m}^{-3}$. No score is given when the time difference is greater than 24 hours, or the concentration difference is greater than $300 \mu \mathrm{g} \mathrm{m}^{-3}$.

\begin{tabular}{|c|c|c|c|c|c|}
\hline Score & 4 & 3 & 2 & 1 & 0 \\
\hline $\begin{array}{c}\text { Arrival time } \\
\text { difference }\end{array}$ & $<3 \mathrm{hr}$ & $<6 \mathrm{hr}$ & $<12 \mathrm{hr}$ & $<24 \mathrm{hr}$ & $>24 \mathrm{hr}$ \\
\hline Duration & $<3 \mathrm{hr}$ & $<6 \mathrm{hr}$ & $<12 \mathrm{hr}$ & $<24 \mathrm{hr}$ & $>24 \mathrm{hr}$ \\
\hline Concentration & $<50 \mu \mathrm{g} \mathrm{m}^{-3}$ & $<100 \mu \mathrm{g} \mathrm{m}^{-3}$ & $<200 \mu \mathrm{g} \mathrm{m}^{-3}$ & $<300 \mu \mathrm{g} \mathrm{m}^{-3}$ & $>300 \mu \mathrm{g} \mathrm{m}^{-3}$ \\
\hline
\end{tabular}

include only particles with radii smaller than $5 \mu \mathrm{m}$. Note that the relevant parameters were read directly from the graphic output of these two modeling systems, because the original model results were unavailable. As errors were unavoidable during this manual process, coarse scoring intervals were applied to minimize the uncertainties.

Due to the affects of local pollution, the temporal and spatial coverage of the dust incursion was not easily identified from the $\mathrm{PM}_{10}$ hourly observation, particularly for the southern part of Taiwan. Therefore, northern Taiwan was the focus area for model evaluation. Note that since this evaluation gave primacy to the region of northern Taiwan, a higher score here does not guarantee that the model can also perform well for other regions. Furthermore the evaluation might not be altogether reliable because the observed $\mathrm{PM}_{10}$ concentration included materials other than mineral dust (cf. Chou et al. 2004; Lung et al. 2004; Hsu et al. 2004; Wang et al. 2004; Yuan et al. 2004), and reliable methods of extraction were not available.

As shown in Table 3, the TAQM/kosa model had the best "local" performance in both years. According to the preliminary analysis, this superiority stems in part from the higher grid resolutions $(81 \mathrm{~km} \times 81 \mathrm{~km})$ applied in TAQM/kosa (and MM5), which are greater than in NAAPS (but not CFORS). The accuracy of the results is understandable since meteorological fields strongly influence the deflation and transport of the yellow dust. This might also be due to the dust deflation module applied (Wang et al. 2000), which might be better equipped to describe conditions for the East Asia region. Whether or not the performance of TAQM in the transport calculation is also superior requires further investigation. Note that the scores of TAQM/kosa have improved from 2002 to 2003 while the scores of other models have declined. After the operation period in 2002 the dust scheme was enhanced (such as to include wet scavenging), and these improvements were immediately reflected in the scores of 2003 . The decline of performance in 2003 for other models was probably due to weaker synoptic weather systems, which require a more sensitive model to catch dust episodes. TAQM/kosa performed 
Table 3. Comparisons of model performance on the forecast of a dust incursion over Taiwan between different operation models: TAQM/kosa was the model used in this study; Chemical weather Forecasting System (CFORS) was developed by the Kyushu University (Japan) group; the Navy Aerosol Analysis and Prediction System (NAAPS) was developed by the Naval Research Laboratory. The mark "X" indicates the information was not available, and this item is not counted in deriving the overall score.

\begin{tabular}{|c|c|c|c|c|c|}
\hline Year & Model & Arrival Time & Duration & $\begin{array}{c}\text { Maximum } \\
\text { concentration }\end{array}$ & $\begin{array}{c}\text { Overall } \\
\text { score }\end{array}$ \\
\hline \multirow{2}{*}{2002} & TAQM/kosa & 2.1 & 2.1 & 1.9 & 2.0 \\
\cline { 2 - 6 } & NAAPS & 2.1 & 1.1 & 2.4 & 1.9 \\
\cline { 2 - 6 } & CFORS & 1.7 & 1 & 1.8 & 1.5 \\
\hline \multirow{2}{*}{2003} & TAQM/kosa & 3.1 & 2.0 & 2.7 & 2.6 \\
\cline { 2 - 6 } & NAAPS & 2.1 & 1.1 & 1.9 & 1.7 \\
\cline { 2 - 6 } & CFORS & 0.1 & $X$ & 0.5 & 0.3 \\
\hline
\end{tabular}

well in predicting the arrival time, but less so for duration and maximum mass concentration.

Note that there were uncertainties in defining the episode duration due to two factors. Firstly, the dissipation of dust is normally not as dramatic as the arrival, particularly in the returning flow situation, where the build up of local pollution is enhanced sufficiently to contaminate the signals. Secondly, multiple waves of dust that originated at different times or in different locations could arrive within a short time span or even simultaneously. Consequently, it is not always apparent from observation data whether multiple peaks were due to one or more events.

\section{CONCLUSIONS}

We applied a three-dimensional Eulerian model-TAQM/kosa— to simulate the generation of dust storms in northern China and Mongolia, and the subsequent transport of yellow dust to other areas by the weather systems. A total of 13 events that brought dust to Taiwan 
during February May of 2002 and 2003 were simulated and analyzed. The three dimensional structures of dust distribution and their movement were well captured by the model, developed for this study, and this capability contributed to an understanding of the transport process of yellow dust events. The yellow dust was found to be transported to Taiwan either via a direct-inland route or a detour through the East China Sea and arrived by riding with the returning flow of the ocean-bound cutoff highs, and the latter was found to travel much longer. Also, neither route was confined to the surface. Quite often the dust that reached Taiwan was initially lifted to mid to upper troposphere then gradually descended due to either a large-scale subsidence or gravitational settlement. These unique features cannot be revealed by conventional meteorological observations or satellite observations. The characteristics of the 2003 episodes were different from those of 2002, and a change in climate patterns, in particular the weakening of the Mongolian high and Aleutian low dipole system, seems to be the main cause.

The amount of dust transported to the Pacific Ocean was no less than that to Taiwan according to our simulations. On seasonal average, about $10 \sim 20 \mu \mathrm{g} \mathrm{m}^{-3}$ of yellow dust was transported to the East China Sea and the western North Pacific, while $30 \sim 50 \mu \mathrm{g} \mathrm{m}^{-3}$ entered the westerly during spring. Only $5 \sim 10 \mu \mathrm{g} \mathrm{m}^{-3}$ of dust reached the surface of the South China Sea, but the concentration aloft might still exceed $100 \mu \mathrm{g} \mathrm{m}^{-3}$.

Simulations performed for 2002 - 2003 support use of the regional dust deflation and transport model TAQM/kosa for operational forecasts of dust incursion events over Taiwan. The numerical simulations examined in this study substantially improve the capacity to forecast dust incursion events, for the purpose of providing a few days of lead time for both healthhazard warnings and the preparation of scientific field operations. The performance of the model, developed for the study, was found to be superior to other operational models that focused on the East Asia region, in forecasting dust incursion events over Taiwan, but there is still room for improvement, particularly in estimating the concentration of dust load. Further application of this model could focus on the role of dust in atmospheric chemistry, cloud microphysics, and marine ecosystems.

Acknowledgments The Environment Protection Administration of Taiwan, R. O. C., under Grants EPA-91-U1L1-02-108 and EPA-92-U1L1-02-102, supported this study. Mr. Chi-Bao Fu's assistance in producing graphics for this paper is greatly appreciated.

\section{REFERENCES}

Bott, A., 1989: A positive definite advection scheme obtained by nonlinear renormalization of the advective fluxes. Mon. Wea. Rev., 117, 1006-1015.

Chen, G. T. J., and H. J. Chen, 1987: Study on large-scale features of dust storm systems in East Asia. Meteor. Res., 10, 57-80.

Chin, M., P. Ginoux, R. Lucchesi, B. Huebert, R. Weber, T. Anderson, S. Masonis, B. Blomquist, A. Bandy, and D. Thornton, 2003: A global aerosol model forecast for the ACE-Asia field experiment. J. Geophys. Res., D108, DOI: 10.1029/2003JD003642. 
Chou, C. K., C. Y. Lin, T. K. Chen, S. C. Hsu, S. C. Lung, S. C. Liu, and C. Y. Young, 2004: Influence of long-range transport dust particles on local air quality: A case study on the Asian dust episodes in Taipei during the spring of 2002. TAO, 15, 881-899.

Duce, R. A., C. K. Unni, and B. J. Bay, 1980: Long-range atmospheric transport of soil dust from Asia to the Tropical North Pacific: Temporal variability. Science, 209, 15221423.

Duce, R. A., 1986: The impact of atmospheric nitrogen, phosphorus, and iron species on marine biological productivity. In: Buat-Menard P. (Ed.), The Role of Air-Sea Exchange in Geochemical Cycling, D. Reidel Publishing Company, 497-529.

Eppley, R. W., 1980: Estimating phytoplankton growth rates in the central oligotrophic oceans. In: Falkowski P. G. (Ed.), Primary Productivity in the Sea, Plenum, New York, 231242.

Guieu, C., M. D. Loÿe-pilot, C. Ridame, and C. Thomas, 2002: Chemical characterization of the Saharan dust end-menber; some biological implications for the western Mediterranean. J. Geophys. Res., 10.1029/2001JD000582.

Heald, C. L., D. J. Jacob, A. M. Fiore, et al., 2003: Asian outflow and trans-Pacific transport of carbon monoxide and ozone pollution: An integrated satellite, aircraft, and model perspective. J. Geophys. Res., D108, DOI: 10.1029/2003JD003507.

Hsu, S. C., S. C. Liu, C. Y. Lin, R. T. Hsu, Y. T. Huang, and Y. W. Chen, 2004: Metal Compositions of $\mathrm{PM}_{10}$ and $\mathrm{PM}_{2.5}$ aerosols in Taipei during Spring, 2002.TAO, 15, 925-948.

Liu, K. Y., and L. F. Hsaio, 2004: A composite comparative study of the dust events in Taipei and Beijing. TAO, 15, 983-998.

Liu, M., D. L. Westphal, S. Wang, A. Shimizu, N. Sugimoto, J. Zhou, and Y. Chen, 2003: A high-resolution numerical study of the Asian dust storms of April 2001.J. Geophys. Res., D108, DOI: 10.1029/2002JD003178.

Lung, S. C. C., C. H. Liu, S. Y. Huang, T. J. Lin, C. K. Chou, and S. C. Liu, 2004: Watersoluble Ions of Aerosols in Taipei in Spring 2002. TAO, 15, 901-923.

Martine, J. H., 1990: Glacial-interglacial $\mathrm{CO}_{2}$ change: The iron hypothesis. Paleooceanography, 5, 1-13.

Merrill, J. T., M. Uematsu, and R. Bleck, 1989: Meteorological analysis of long range transport of mineral aerosols over the Pacific. J. Geophys. Res., 94, 8584-8598.

Nickovic, S., G. Kallos, A. Papadopoulos, and O. Kakaliagou, 2001: A model for prediction of desert dust cycle in the atmosphere. J. Geophys. Res., D106, 18113-18129.

Pleim, J. E., and J. S. Chang, 1992: A non-local closure model for vertical mixing in the convective boundary layer. Atmos. Environ., 26A, 965-981.

Sun, J., M. Zhang, and T. Liu, 2001: Spatial and temporal characteristics of dust storms in China and its surrounding regions, 1960-1999: Relations to source area and climate.J. Geophys. Res., 106, 10325-10333.

Uno, I., G. R. Carmichael, D. Streets, S. Satake, T. Takemura, J. H. Woo, M. Uematsu, and S. Ohta, 2003: Analysis of surface black carbon distributions during ACE-Asia using a regional-scale aerosol model. J. Geophys. Res., D108, DOI: 10.1029/2002JD003252. 
Wang, C. C., C. T. Lee, S. C. Liu, and J. P. Chen, 2004: Aerosol characterization at Taiwan's Northern tip during ACE-Asia. TAO, 15, 839-855.

Wang, Z., H. Ueda, and M. Huang, 2000: A deflation module for use in modeling long-range transport of yellow sand over East Asia.J. Geophys. Res., 105, 26947-26959.

Wang, Z., T. Maeda, M. Hayashi, L. Hsiao, and K. Liu, 2001: A Nested Air Quality Prediction Modeling System for Urban and Regional Scales: Application for High-Ozone Episode in Taiwan. Water, Air, Soil Pollut., 130, 391-396.

Westphal, D. L., O. B. Toon, and T. N. Carlson, 1988: A case study of mobilization and transport of Saharan dust. J. Atmos. Sci., 45, 2145-2175.

Wilkening, K. E., L. A. Barrie, and M. Engle, 2000: Trans-Pacific air pollution. Science, 290, 65-66.

Young, C. Y., K. H. Lee, and C. M. Liu, 1997: A comparison of air-quality data obtained during a dust-storm event and a local pollution episode - March 12 16, 1995.J. Environ. Protection Soc. R.O.C., 20, 1-38.

Young, R. W., et al., 1991: Atmospheric iron inputs and primary productivity: Phytoplankton responses in the North Pacific. Global Biogeochem. Cycles, 5, 119-134.

Yuan, C. S., C. C. Sau, M. C. Chen, M. H. Huang, S. W. Chang, and Y. C. Lin, 2004: Mass Concentration and Size-Resolved Chemical Composition of Atmospheric Aerosols Sampled at Pencadores Islands During Asian Dust Storm Periods in the Year of 2001 and 2002. TAO, 15, 857-879. 